\title{
Y ESTUDO COMPARATIVO ENTRE OS PROCEDIMENTOS METODOLÓGICOS E OS RESULTADOS DOS INDICADORES DE MONITORAMENTO DA META 17 DO PLANO NACIONAL DE EDUCAÇÃO
}

Mariano Laio de Oliveira ${ }^{1}$

http://dx.doi.org/10.24109/9786581041076.ceppe.v2a5

\section{RESUMO}

Este artigo objetiva comparar os procedimentos metodológicos e os resultados dos indicadores de monitoramento da Meta 17 do Plano Nacional de Educação (PNE) publicados pelo Instituto Nacional de Estudos e Pesquisas Educacionais Anísio Teixeira (Inep), tendo em vista a substituição da Pesquisa Nacional por Amostra de Domicílio (Pnad) pela Pesquisa Nacional por Amostra de Domicílio Contínua (Pnad Contínua) efetivada pelo Instituto Brasileiro de Geografia e Estatística (IBGE). Durante os anos de 2012 e 2015, período em que as pesquisas foram realizadas concomitantemente, verificou-se que o indicador calculado com dados da Pnad apresentou percentuais mais elevados do que o indicador da Pnad Contínua. No entanto, os rendimentos brutos médios mensais mensurados pelo indicador da Pnad, tanto para os profissionais do magistério da educação básica como para os demais profissionais, apresentaram valores reais inferiores aos observados pelo indicador da Pnad Contínua.

Palavras-chave: indicadores de remuneração; remuneração docente; valorização docente.

\footnotetext{
1 Mariano Laio de Oliveira é graduado em ciências econômicas pelo Centro Universitário de Brasília (UniCeub), em geologia pela Universidade de Brasília (UnB) e mestre em administração pública pela UnB. É da carreira de Pesquisador-Tecnologista em Informações e Avaliações Educacionais do Instituto Nacional de Estudos e Pesquisas Educacionais Anísio Teixeira (Inep). Dedica-se a temas como remuneração e carreiras dos profissionais do magistério e financiamento da educação com ênfase no Fundo de Manutenção e Desenvolvimento da Educação Básica e de Valorização dos Profissionais de Educação (Fundeb).
} 


\section{INTRODUÇÃO}

A valorização dos profissionais do magistério representa um dos pilares fundamentais para o desenvolvimento da educação básica pública brasileira. Um amplo arcabouço legal preconiza a garantia da valorização desses profissionais. Essa valorização está prevista entre os oito princípios que norteiam o ensino, elencados no art. 206 da Constituição Federal (CF) de 1998. Tais princípios garantem aos profissionais da educação escolar, na forma da lei, planos de carreira com ingresso exclusivamente por concurso público de provas e títulos. A lei federal que estabelece as diretrizes e bases da educação nacional (Lei n 9.394/96) também traz, em seu art. $3^{\circ}$, princípios sobre os quais o ensino será ministrado, dentre eles, o inc. VII, que prevê a valorização do profissional da educação escolar. Igualmente, o Plano Nacional de Educação (PNE) 2014-2024 dispõe, dentre outras diretrizes, sobre a valorização dos profissionais da educação (Lei $\mathrm{n}^{0} 13.005 / 14$ ).

O processo de valorização dos profissionais do magistério compreende diversos aspectos, dentre eles, a formação inicial e continuada, as condições laborais adequadas ao ambiente escolar, o ingresso na carreira mediante aprovação em concurso público, a jornada de trabalho adequada (com dois terços da carga horária para atividades de interação com os educandos), a estruturação de cargos com planos de carreiras e o atingimento de condições condignas de remuneração, tendo em vista o cumprimento do piso salarial profissional nacional da categoria (Lei $\mathrm{n}^{0} 11.738 / 08$ ).

No que diz respeito ao atingimento de condições condignas de remuneração, a Meta 17 do PNE 2014-2024 objetiva valorizar os profissionais do magistério das redes públicas de educação básica de forma a equiparar seu rendimento médio ao dos demais profissionais do mercado de trabalho com nível de escolaridade equivalente. A Estratégia 17.2 determina o acompanhamento da evolução salarial desses profissionais por meio da construção de indicadores baseados na Pesquisa Nacional por Amostra de Domicílios (Pnad), do Instituto Brasileiro de Geografia e Estatística (IBGE).

Organismos internacionais, como a Organização para a Cooperação e Desenvolvimento Econômico (OCDE) - por meio do anuário Education at a Glance (OECD, 2017) -, organizações da sociedade civil brasileira (Departamento Intersindical de Estatística e Estudos Socioeconômicos - Dieese, 2014; Todos pela Educação, 2015) e entidades do governo federal, como o Instituto Nacional de Estudos e Pesquisas Educacionais Anísio Teixeira - Inep (Brasil. Inep, 2015) fazem uso de indicadores fundamentados no rendimento médio dos professores e dos demais profissionais com escolaridade equivalente para avaliar o prosseguimento das políticas públicas de remuneração dos docentes da educação básica.

Estudos acadêmicos empregaram o parâmetro do rendimento médio como indicador para calcular a razão entre a remuneração dos professores da educação básica e a dos demais profissionais não professores. Diferentes estudos calcularam seus indicadores utilizando a base de dados da Pnad (Moriconi, 2008; Brito; Waltenberg, 2014; Jacomini; Alves; Camargo, 2016). 
Alves e Sonobe (2018) apontam que há divergências nos resultados obtidos dos indicadores de rendimentos médios dos professores da educação básica divulgados nas diferentes publicações de instituições, da academia e da sociedade civil. Tais divergências ocorrem inclusive em estudos que fizeram uso das mesmas bases de dados. Essa constatação evidencia que as escolhas metodológicas arbitradas na elaboração e na composição de indicadores não são um procedimento imparcial (Alves; Sonobe, 2018). Habitualmente, tais escolhas se dão com base em critérios teóricos, legais e políticos envolvidos na construção do indicador (Jannuzzi, 2005). No caso dos indicadores abordados neste artigo, as escolhas metodológicas buscaram atender estritamente aos critérios legais postulados no caput da Meta 17 do PNE.

É imprescindível contextualizar que, a partir de 2006, o IBGE promoveu a efetivação progressiva do Sistema Integrado de Pesquisas Domiciliares (SIPD), visando reformular suas pesquisas nesse âmbito. Dentre os estudos que compõem o SIPD, está a Pesquisa Nacional por Amostra de Domicílios Contínua (Pnad Contínua) que, a partir de 2012, foi instituída para substituir as estatísticas sobre mercado de trabalho obtidas por meio da Pnad e da Pesquisa Mensal de Emprego (PME). Tal procedimento teve o intuito de potencializar os resultados produzidos por ambas as pesquisas. Portanto, com a introdução da Pnad Contínua, procedeu-se à ampliação da cobertura da PME para todo o território nacional e as informações da Pnad sobre trabalho passaram a ser disponibilizadas com periodicidade apropriada para a realização de análises conjunturais do tema (IBGE, 2018). Assim, diante das mudanças nas pesquisas domiciliares do IBGE, fez-se necessário adotar a Pnad Contínua como nova fonte oficial de dados para balizar o cálculo do indicador erigido pelo PNE para acompanhar e monitorar a Meta 17.

Este artigo tem como objetivo demonstrar as mudanças e as escolhas metodológicas realizadas na construção do indicador da Meta 17 do PNE, tendo em vista a substituição da base de dados da Pnad pela Pnad Contínua, assim como apresentar análise descritiva comparando os resultados obtidos de ambas as pesquisas. Visa, ainda, destacar os aperfeiçoamentos metodológicos aplicados no indicador da Meta 17, calculado com dados da Pnad, que foi divulgado no Plano Nacional de Educação PNE 2014-2024: Linha de Base e no Relatório do $1^{\circ}$ Ciclo de Monitoramento das Metas do PNE: biênio 2014-2016. Este estudo se justifica por apresentar detalhadamente a metodologia adotada para compor o atual indicador da Meta 17, divulgado pelo Inep com base no Relatório do $2^{\circ}$ Ciclo de Monitoramento das Metas do PNE - 2018.

O artigo é dividido em três seções. A primeira seção aborda a questão metodológica por meio da comparação dos parâmetros arbitrados na construção dos indicadores da Meta 17 do PNE, calculados da Pnad e da Pnad Contínua. A segunda seção abrange a análise comparativa dos resultados e a discussão sobre suas diferenças. Por fim, a última seção dispõe sobre as considerações finais. 


\section{METODOLOGIA}

A metodologia de construção do indicador de monitoramento da Meta 17 do PNE 2014-2024 buscou traduzir de modo mais acurado possível os critérios e os parâmetros estabelecidos pelo caput:

Meta 17 - valorizar os (as) profissionais do magistério das redes públicas de educação básica de forma a equiparar seu rendimento médio ao dos (as) demais profissionais com escolaridade equivalente, até o final do sexto ano de vigência deste PNE. (Brasil, 2014).

Com base no enunciado no caput da Meta 17 é possível depreender que ao menos seis parâmetros básicos devem estar presentes na composição do indicador que irá mensurar o rendimento médio dos profissionais do magistério das redes públicas de educação básica e dos demais profissionais. São eles:

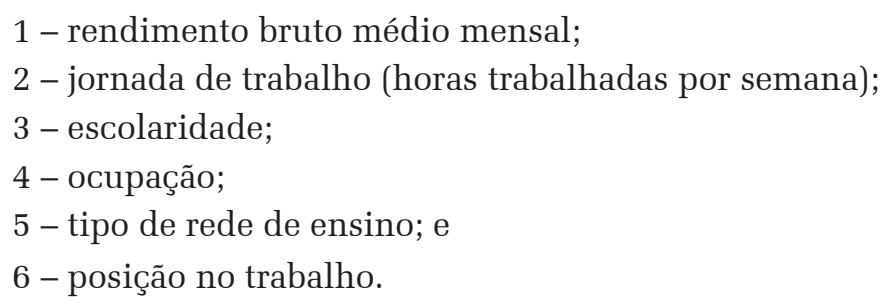

Portanto, o indicador da Meta 17, calculado utilizando como base de dados a Pnad, apresentava a seguinte descrição e fórmula de cálculo:

Razão entre o salário médio de professores da educação básica da rede pública (não federal) e o salário médio de não professores com escolaridade equivalente.

Fórmula de cálculo resumida:

salário médio dos professores da educação básica, na rede puública (não federal), com ao menos 12 anos de escolaridade x 100

salário médio dos não professores, com ao menos 12 anos de escolaridade

Já o indicador de monitoramento da Meta 17, calculado com base nos dados da Pnad Contínua, apresentou a seguinte descrição e fórmula de cálculo:

Percentual do rendimento bruto médio mensal dos profissionais do magistério das redes públicas da educação básica, com nível de instrução superior completo, em relação ao rendimento bruto médio mensal dos demais profissionais assalariados, com escolaridade equivalente. 
Fórmula de cálculo resumida:

rendimento bruto médio mensal dos profissionais do magistério das redes públicas de educação básica, com nível de instrução superior completo

rendimento bruto médio mensal dos demais profissionais assalariados,

com nível de instrução superior completo

O Quadro 1 traz o comparativo entre as variáveis da Pnad e da Pnad Contínua que foram utilizadas para construir os indicadores de monitoramento da Meta 17 do PNE.

QUADRO 1

\section{COMPARATIVO DAS VARIÁVEIS DA PNAD E DA PNAD CONTÍNUA UTILIZADAS NA COMPOSIÇÃO DOS INDICADORES DE MONITORAMENTO DA META 17 DO PNE - BRASIL}

\begin{tabular}{|c|c|c|}
\hline VARIÁVEIS & PNAD & PNAD CONTINUA \\
\hline $\begin{array}{l}\text { Rendimento } \\
\text { bruto médio } \\
\text { mensal }\end{array}$ & $\begin{array}{l}\text { V9532 - rendimento mensal } \\
\text { em dinheiro que recebia } \\
\text { normalmente, no mês de } \\
\text { referência, no trabalho } \\
\text { principal da semana de } \\
\text { referência }\end{array}$ & $\begin{array}{l}\text { V403312 - qual era o rendimento bruto/ } \\
\text { retirada mensal que... } \\
\text { Recebia/fazia normalmente nesse } \\
\text { trabalho? (Valor em dinheiro) }\end{array}$ \\
\hline $\begin{array}{l}\text { Jornada de } \\
\text { trabalho semanal }\end{array}$ & $\begin{array}{l}\text { V9058 - número de horas } \\
\text { habitualmente trabalhadas } \\
\text { por semana no trabalho } \\
\text { principal da semana de } \\
\text { referência } \\
01 \text { a } 98 \text { hora(s) }\end{array}$ & $\begin{array}{l}\text { V4039 - quantas horas... } \\
\text { Trabalhava normalmente, por semana, } \\
\text { nesse trabalho principal? } \\
01 \text { a } 120 \text { hora(s) }\end{array}$ \\
\hline Escolaridade & $\begin{array}{l}\text { V4803 - anos de estudo } \\
\text { (todas as pessoas) } \\
\text { Categorias: } 13 \text { ( } 12 \text { anos), } 14 \\
\text { (13 anos), } 15 \text { ( } 14 \text { anos), } 16 \\
\text { (15 anos ou mais) }\end{array}$ & $\begin{array}{l}\text { VD3001 - nível de instrução mais } \\
\text { elevado alcançado } \\
\text { (pessoas de } 5 \text { anos ou mais } \\
\text { de idade) } \\
\text { Categorias: } 7 \text { (superior completo) }\end{array}$ \\
\hline Ocupação & $\begin{array}{l}\text { V9906 - código da ocupação } \\
\text { no trabalho principal da } \\
\text { semana de referência } \\
\text { Baseado na "composição } \\
\text { dos grupamentos } \\
\text { ocupacionais" e "relação de } \\
\text { códigos de ocupação" da } \\
\text { CBO-Domiciliar². }\end{array}$ & $\begin{array}{l}\text { V4010 - código da ocupação (cargo ou } \\
\text { função) } \\
\text { Baseado na “composição dos } \\
\text { grupamentos ocupacionais" e } \\
\text { "classificação de ocupações para as } \\
\text { pesquisas domiciliares - COD”»3}\end{array}$ \\
\hline
\end{tabular}




\section{QUADRO 1}

\begin{tabular}{l|l|l|l}
\multicolumn{2}{c}{ COMPARATIVO DAS VARIÁVEIS DA PNAD E DA PNAD CONTÍNUA UTILIZADAS NA } \\
COMPOSIÇÃO DOS INDICADORES DE MONITORAMENTO DA META 17 DO PNE - BRASIL \\
(conclusão)
\end{tabular}

Fontes: Elaboração própria com base no dicionário de variáveis da Pnad/IBGE (arquivo de pessoas) e dicionário das variáveis da Pnad Contínua/IBGE.

Uma vez explicitadas as variáveis utilizadas na composição dos indicadores, a descrição das fórmulas detalhadas de ambos é apresentada a seguir:

2 Relação de códigos de ocupação da Classificação Brasileira de Ocupações Domiciliar (CBO-Domiciliar) referentes aos profissionais do ensino (com formação de nível superior): 2311 - Professores da educação infantil; 2312 - Professores do ensino fundamental (séries iniciais); 2313 - Professores do ensino fundamental (séries finais); 2321 - Professores do ensino médio; 2330 - Professores e instrutores do ensino profissional; 2391 - Professores de educação física; 2392 - Professores de alunos com deficiências físicas e mentais. Professores leigos e de nível médio: 3311 - Professores na educação infantil; 3312 Professores no ensino fundamental (séries iniciais); 3313 - Professores no ensino profissionalizante; 3321 - Professores leigos na educação infantil e no ensino fundamental; 3322 - Professores leigos no ensino profissionalizante.

3 Relação de códigos de ocupação da Classificação de Ocupações para as Pesquisas Domiciliares (COD) referentes aos profissionais do ensino: 2320 - Professores de formação profissional; 2330 - Professores do ensino médio; 2341 - Professores do ensino fundamental; 2342 - Professores do ensino pré-escolar; 2351 - Especialistas em métodos pedagógicos; 2352 - Educadores para necessidades especiais; 2353 - Outros professores de idiomas; 2354 - Outros professores de música; 2355 - Outros professores de artes; 2356 - Instrutores em tecnologias da informação; 2359 - Profissionais do ensino não classificados anteriormente. 
Fórmula de cálculo detalhada do indicador com variáveis da Pnad:

$$
\begin{aligned}
& {\left[\frac{V 9532}{10 h \leq V 9058 \leq 60 h} X 40\right] \text { se } V 4803 \geq 13 \text { e } V 4803<17 \text { e V9033 }=(3 \text { ou } 5) \text { e }} \\
& \text { V9906 }=(2311,3311,2391,2392,2312,2313,3312,3321,2321,2330,3313 \text { ou 3322 })
\end{aligned}
$$

$$
\left[\frac{\mathrm{V} 9532}{10 \mathrm{~h} \leq \mathrm{V} 9058 \leq 60 \mathrm{~h}} X 40\right] \text { se } V 4803 \geq 13 \text { e V4803<17 e }
$$

V9906 $\neq(2311,3311,2391,2392,2312,2313,3312,3321,2321,2330,3313,3322$ ou 2340$)$

Fórmula de cálculo detalhada do indicador com variáveis da Pnad Contínua:

$$
\begin{aligned}
& {\left[\frac{V 403312}{10 h \leq V 4039 \leq 60 h} X 40\right] \text { se } V D 3001=7 \text { e } V 4014=(1 \text { ou } 2 \text { ou } 3) e} \\
& \mathrm{~V} 4010=(2320,2330,2341,2342,2351,2352,2353,2354,2355,2356 \text { ou } 2359) \\
& \text { Ind } 17= \\
& {\left[\frac{\mathrm{V} 403312}{10 \mathrm{~h} \leq \mathrm{V} 4090 \leq 60 \mathrm{~h}} \times 40\right] \text { se VD3001 }=7 \text { e V4012=(2 ou } 3 \text { ou 4) } e} \\
& \mathrm{~V} 4010 \neq(2310,2320,2330,2341,2342,2351,2352,2353,2354,2355,2356 \text { ou } 2359)
\end{aligned}
$$

Para dar início à descrição dos procedimentos de cálculo do indicador de monitoramento da Meta 17, será apresentado o método de construção da variável derivada que representa o "rendimento bruto médio mensal ponderado em 40 horas semanais”. Trata-se da variável principal do estudo que, uma vez constituída, utilizará as demais variáveis apenas como filtros para especificar quesitos como ocupação, escolaridade, rede de ensino e profissionais assalariados. O procedimento metodológico para a construção da variável principal é comum a ambos os indicadores, ou seja, tanto o indicador calculado com dados da Pnad como o com dados da Pnad Contínua apresentam a mesma expressão matemática para calcular a variável "rendimento bruto médio mensal ponderado em 40 horas semanais”, exigindo apenas a substituição de suas respectivas variáveis (rendimento bruto mensal e jornada de trabalho semanal).

No caso da Pnad foram utilizadas as variáveis V9532 e V9058 que, na Pnad Contínua, correspondem, respectivamente, às variáveis V403312 e V4039. No que diz respeito ao parâmetro "carga horária de trabalho semanal” (V9058 na Pnad e V4039 na Pnad Contínua) foram estabelecidas delimitações para selecionar apenas as observações em que a jornada fosse enquadrada entre 10 e 60 horas semanais trabalhadas. As expressões matemáticas das variáveis principais "rendimento bruto médio mensal ponderado em 40 horas semanais” são: 
Para a Pnad: $\left[\frac{\text { V9532 }}{10 \mathrm{~h} \leq \text { V9058 } \leq 60 \mathrm{~h}} X 40\right] \quad$ Para a Pnad Contínua: $\left[\frac{\text { V403312 }}{10 \mathrm{~h} \leq \mathrm{V} 4039 \leq 60 \mathrm{~h}}\right.$ 40 $]$

As etapas seguintes do cálculo do indicador selecionaram as variáveis "filtros" destinadas a especificar os profissionais do magistério da educação básica, ou seja, os numeradores das Equações 1 e 2 descritas anteriormente. Os filtros de seleção permitiram identificar os seguintes parâmetros:

1 - ocupações referentes aos profissionais do magistério da educação básica;

2 - tipo de rede de ensino (federal, estadual e municipal); e

3 - escolaridade dos profissionais do magistério.

O processo de seleção das ocupações dos profissionais do magistério da educação básica apresentou algumas diferenças entre a Pnad e a Pnad Contínua. No caso da Pnad, os códigos de ocupação eram classificados com base na relação de códigos da Classificação Brasileira de Ocupações Domiciliar - CBO-Domiciliar. Os códigos CBO-Domiciliar selecionados para o numerador do indicador da Pnad consideraram apenas os professores da educação básica.

No caso da Pnad Contínua, os códigos de ocupação são classificados de acordo com a Classificação de Ocupações para as Pesquisas Domiciliares - COD. A seleção dos códigos da COD levou em conta a ampliação do rol de ocupações para abarcar, além dos professores da educação básica, outros profissionais do magistério da educação básica. ${ }^{4} \mathrm{~A}$ ampliação desse rol se justifica por atender fidedignamente à letra da lei da Meta 17 do PNE, que prevê "valorizar os (as) profissionais do magistério...” (Brasil, 2014, Anexo, Meta 17, caput). A única exceção foi o código 2310 que se refere aos professores de universidades e do ensino superior.

No que diz respeito às ocupações consideradas para a composição do grupo dos "demais profissionais" foram selecionados todos os códigos de ocupações não identificados como professores, ou seja, foram desconsideradas todas as ocupações dentre os profissionais do ensino listados na CBO-Domiciliar, registrados como professores (no caso da Pnad). No que se refere à Pnad Contínua, para compor o grupo dos "demais profissionais" foram selecionados todos os códigos de ocupações não identificados como profissionais do magistério, ou seja, foram excluídas todas as ocupações listadas na COD como profissionais do ensino.

\footnotetext{
4 "Por profissionais do magistério público da educação básica entendem-se aqueles que desempenham as atividades de docência ou as de suporte pedagógico à docência, isto é, direção ou administração, planejamento, inspeção, supervisão, orientação e coordenação educacionais, exercidas no âmbito das unidades escolares de educação básica, em suas diversas etapas e modalidades, com a formação mínima determinada pela legislação federal de diretrizes e bases da educação nacional” (Brasil, 2008, art. $2^{\circ}, \S 2^{\circ}$ ).
} 
O parâmetro "tipo de rede de ensino" foi definido com base nas variáveis V9033 (Pnad) e V4014 (Pnad Contínua). A rede de ensino federal não foi considerada no cálculo do indicador da Pnad. No caso do indicador da Pnad Contínua, optou-se por incluir a rede de ensino federal no rol das redes consideradas. Tal inclusão foi arbitrada visando atender à literalidade da redação da Meta 17 do PNE, que prevê “(...) profissionais do magistério das redes públicas de educação básica (...)” (Brasil, 2014, Anexo, Meta 17, caput).

O parâmetro "escolaridade" pode ser dimensionado nas pesquisas domiciliares do IBGE por meio de duas variáveis: "anos de estudo" ou "nível de instrução mais elevado alcançado". A opção arbitrada para calcular o indicador da Pnad foi a variável V4803 "anos de estudo", em que foram selecionadas todas as observações que apresentassem 12 ou mais anos de estudo completos. Em termos relativos, 12 anos de estudo equivalem ao nível de instrução acadêmica de um indivíduo com ensino médio completo (11 anos de estudo) adicionado um ano de estudo concluído no ensino superior. Algumas distorções foram constatadas com relação à escolha da variável "anos de estudo" quando confrontada com a variável "nível de instrução".

Primeiro, as vagas de emprego disponíveis no mercado de trabalho brasileiro se pautam normalmente pelo nível de instrução do profissional, ou seja, são vagas que exigem do candidato a formação de nível fundamental completo, nível médio completo ou nível superior completo (em alguns casos, até mesmo mestrado ou doutorado). Não é comum serem ofertadas vagas de emprego que demandem profissionais que possuam nível médio completo e pelo menos um ano do ensino superior concluído, tal como o critério definido para calcular o indicador com dados da Pnad. Ainda, nos planos de carreira ou tabelas de vencimentos das redes de ensino públicas não há previsão de profissionais com esse nível de formação (12 anos ou mais de estudo). Segundo a Lei $\mathrm{n}^{\circ}$ 9.394/96, os professores devem possuir nível médio ou nível superior. Desse modo, o recorte impróprio em relação ao nível de formação embaralha, indiscriminadamente, em um mesmo grupo, profissionais de níveis acadêmicos médio e superior.

Segundo, ao realizar investigações na base de dados da Pnad, por meio do cruzamento entre as variáveis "anos de estudo" e "nível de instrução”, constatou-se que a estimativa percentual de professores com pelo menos 12 anos de escolaridade, que possuem nível superior completo, representou 79,2\% do contingente de docentes no ano de 2007 (ver Tabela 1). 
TABELA 1

DISTRIBUIÇÃO PERCENTUAL DA AMOSTRA EXPANDIDA DE PROFESSORES COM PELO MENOS 12 ANOS DE ESCOLARIDADE, POR NÍVEL DE INSTRUÇÃO - BRASIL - 2007-2014

\begin{tabular}{|l|r|r|r|r|r|r|r|}
\hline $\begin{array}{c}\text { NÍVEL DE } \\
\text { INSTRUÇÃ }\end{array}$ & 2007 & 2008 & 2009 & 2011 & 2012 & 2013 & 2014 \\
\hline $\begin{array}{l}\text { Nível médio } \\
\text { Superior }\end{array}$ & $1,8 \%$ & $1,1 \%$ & $1,5 \%$ & $1,1 \%$ & $2,0 \%$ & $1,2 \%$ & $1,3 \%$ \\
\hline $\begin{array}{l}\text { incompleto } \\
\text { Superior }\end{array}$ & $19,1 \%$ & $17,5 \%$ & $14,0 \%$ & $15,3 \%$ & $12,7 \%$ & $11,3 \%$ & $9,6 \%$ \\
\hline \begin{tabular}{l} 
completo \\
\hline
\end{tabular}
\end{tabular}

Fonte: Elaboração própria com base em dados da Pnad/IBGE 2007-2014.

Ao longo da série histórica, essa taxa apresentou evolução de 9,9 pontos percentuais (p.p.), perfazendo 89,1\% da estimativa de professores com nível superior completo para o ano de 2014 (ver Tabela 1).

Quanto ao grupo dos demais profissionais com pelo menos 12 anos de escolaridade, os dados da Pnad demonstraram que, em 2007, 61\% desses profissionais possuíam instrução de nível superior (ver Tabela 2). Ao longo da série, o contingente dos demais trabalhadores com formação superior completa apresentou avanço de apenas 2,4 p.p., perfazendo 63,6\% em 2014. Percebe-se que o indicador calculado com dados da Pnad não apresenta equivalência de escolaridade na composição dos grupos dos professores e dos demais profissionais, uma vez que o indicador concentra, no lado dos professores (numerador), quase a totalidade com formação de nível superior $(89,1 \%$, em 2014) enquanto que, no lado dos demais profissionais (denominador), algo mais do que a metade possui formação de nível superior (63,6\%, em 2014).

TABELA 2

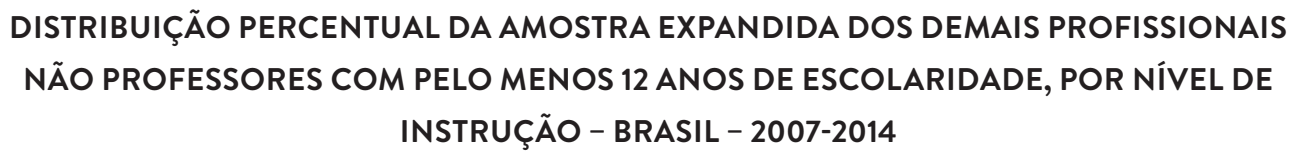

\begin{tabular}{|c|c|c|c|c|c|c|c|}
\hline $\begin{array}{l}\text { NIVEL DE } \\
\text { INSTRUÇÃOO }\end{array}$ & 2007 & 2008 & 2009 & 2011 & 2012 & 2013 & 2014 \\
\hline Nível médio & $2,8 \%$ & $3,1 \%$ & $3,4 \%$ & $3,5 \%$ & $7,0 \%$ & $6,8 \%$ & $6,5 \%$ \\
\hline $\begin{array}{l}\text { Superior } \\
\text { incompleto }\end{array}$ & $36,1 \%$ & $34,5 \%$ & $33,6 \%$ & $31,3 \%$ & $29,5 \%$ & $29,3 \%$ & $30,0 \%$ \\
\hline $\begin{array}{l}\text { Superior } \\
\text { completo }\end{array}$ & $61,2 \%$ & $62,4 \%$ & $63,0 \%$ & $65,2 \%$ & $63,5 \%$ & $64,0 \%$ & $63,6 \%$ \\
\hline
\end{tabular}

Fonte: Elaboração própria com base em dados da Pnad/IBGE 2007-2014. 
Os dados das Tabelas 1 e 2 evidenciam que o parâmetro de equivalência de escolaridade, aparentemente equiparado por meio da variável "pelo menos 12 anos de estudo", na verdade encobre uma desigualdade no contingente de profissionais de nível médio e superior que compõem os diferentes grupos de professores e dos demais profissionais. Com vistas a atender primordialmente aos preceitos descritos na Meta 17 do PNE, que prevê "valorizar os (as) profissionais do magistério... de forma a equiparar (...) demais profissionais com escolaridade equivalente” (Brasil, 2014, Anexo, Meta 17, caput), optou-se por substituir a variável V4803 (Pnad) pela variável da Pnad Contínua "nível de instrução mais elevado alcançado pelo trabalhador" (VD3001). Assim, a escolaridade arbitrada para calcular o indicador da Pnad Contínua considerou exclusivamente a categoria "nível superior" da variável VD3001, tanto para os profissionais do magistério como para os demais profissionais.

Por fim, decidiu-se incluir mais um parâmetro como "filtro" na composição do denominador do indicador, ou seja, na seleção do grupo dos demais profissionais. Trata-se da variável V4012 da Pnad Contínua, utilizada como proxy capaz de distinguir os profissionais assalariados (com vínculo empregatício ou contrato formal de sua atividade laboral). Nesse caso, foram consideradas para o cálculo do indicador da Pnad Contínua as seguintes categorias: militar do exército, da marinha, da aeronáutica, da polícia militar ou do corpo de bombeiros militar; empregado do setor privado e empregado do setor público (inclusive empresas de economia mista). Tal filtro se justifica por permitir selecionar apenas os demais profissionais que perceberam alguma remuneração mensal regular/ordinária que seja compatível e comparável à remuneração mensal devida aos profissionais do magistério. ${ }^{5}$

Finalizados os procedimentos para calcular o indicador da Meta 17, revelou-se a questão dos valores dos rendimentos brutos médios mensais considerados discrepantes, ou seja, os outliers. Algumas observações para a variável "rendimento bruto médio mensal ajustado para 40 horas semanais", tanto para os profissionais do magistério (numerador) como para os demais profissionais (denominador), apresentaram distorções que influenciam os resultados médios mensais, principalmente quando aferidos no âmbito das unidades da federação (Brasil. Inep, 2018).

A diversidade socioeconômica das unidades federativas brasileiras exige que a equiparação salarial almejada pela Meta 17 seja feita em relação à remuneração bruta média mensal de cada estado. Diante de tal realidade, torna-se necessário aplicar o método de detecção e exclusão de outliers para cada unidade da federação, tanto no grupo dos profissionais do magistério como no dos demais profissionais. Assim, após a detecção e a exclusão dos outliers, em cada uma das 27 unidades da federação, serão consideradas as observações remanescentes como válidas para calcular o indicador no nível "Brasil". Cabe destacar que o procedimento de detecção de outliers deve ser realizado após a ativação da variável de expansão da amostra (variável V4729, no caso da Pnad ou V1028, para a Pnad Contínua).

\footnotetext{
5 As categorias da variável V4012 (Pnad Contínua) desconsideradas foram: trabalhadores domésticos, empregador, trabalhador por conta própria e trabalhador familiar não remunerado.
} 
No indicador calculado com dados da Pnad não foi realizada a detecção de outliers da cauda inferior. Já no caso do indicador calculado com a Pnad Contínua, a metodologia utilizada para a detecção de outliers da cauda inferior foi determinar como ponto de corte os rendimentos brutos médios mensais ajustados para 40 horas semanais que apresentassem valores abaixo do salário mínimo nacional estabelecido para o respectivo exercício.

A metodologia aplicada para a detecção de outliers da cauda superior é idêntica para ambos os indicadores, tanto para o calculado com dados da Pnad como para o com a Pnad Contínua. Utilizou-se o método boxplot, que identifica valores atípicos com base na amplitude interquartil (AIQ) - considerada como a diferença entre o terceiro quartil (Q3) e o primeiro quartil (Q1) da distribuição amostral. Quaisquer observações situadas abaixo de Q1 ou acima de Q3 por mais 1,5 vezes AIQ são classificadas como outliers moderados ou, ainda, são considerados como outliers extremos quaisquer valores situados abaixo de Q1 ou acima de Q3 por mais três vezes AIQ (Fávero; Belfiore, 2017).

Neste artigo, o ponto de corte arbitrado para os rendimentos brutos mensais da cauda superior foi de Q3 por mais seis vezes AIQ. Cabe ressaltar que tal critério de seleção dos casos atípicos é idêntico ao utilizado na pesquisa coordenada pela Gerência Técnica do Censo Demográfico, da Diretoria de Pesquisas do IBGE, denominada Estudos e tratamento da variável rendimento no Censo Demográfico 2010 (IBGE, 2012).

Portanto, para identificar os outliers da cauda superior da distribuição amostral, calculou-se, para cada unidade da federação, o Q1, o Q3 e a AIQ, tanto para o numerador como para o denominador de ambos os indicadores da Meta 17. Surge, então, a regra de seleção de outliers da cauda superior: o resultado do rendimento bruto mensal do profissional deve ser superior a Q3 mais seis vezes a amplitude interquartílica (Brasil. Inep, 2018).

Exemplo:

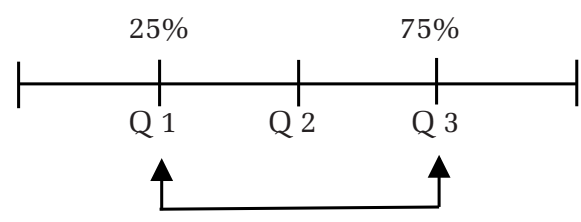

AIQ

FÓRMULA DO CÁLCULO DOS OUTLIERS

Q3 + 6 x AIQ

Os outliers identificados foram excluídos da base de dados antes da execução dos procedimentos descritos para calcular os indicadores da Meta 17, seja com os dados da Pnad, seja com os da Pnad Contínua. 


\section{RESULTADOS E DISCUSSÃO}

Esta seção apresenta uma análise descritiva e compara os resultados obtidos por meio da aplicação das metodologias descritas na seção anterior, utilizando as bases de dados da Pnad e da Pnad Contínua. Para tanto, foram geradas duas séries históricas que abrangem o período de anos em que os dados de ambas as pesquisas domiciliares do IBGE foram coletados concomitantemente. Assim, a série histórica construída com os dados da Pnad abrange os exercícios de 2011 a 2015 (ano em que se encerrou a Pnad), e a série com os dados da Pnad Contínua compreende o período de 2012 a 2018.

As alterações dos resultados dos indicadores se dão por diversos motivos. A principal diferença está na utilização, como fonte de dados, de duas pesquisas domiciliares com distintas características essenciais, tais como: abrangência geográfica, plano amostral, tamanho da amostra e periodicidade da coleta. Além dessas, outras variações dizem respeito às escolhas metodológicas descritas na construção dos indicadores.

No que se refere aos resultados, a Tabela 3 apresenta a comparação entre os resultados obtidos com base nos dados da Pnad e os da Pnad Contínua, aplicando-se as respectivas metodologias em nível nacional. Constatou-se que os indicadores da Meta 17, mensurados com base nos dados da Pnad, apresentaram percentuais superiores aos registrados pela Pnad Contínua ao longo dos quatro anos em que ambas as pesquisas foram coletadas simultaneamente (ver Gráfico 1 e Tabela 3). Ao final do artigo, os Anexos A e B apresentam os resultados obtidos para ambas as bases de dados (Pnad e Pnad Contínua), discriminados por unidades da federação.

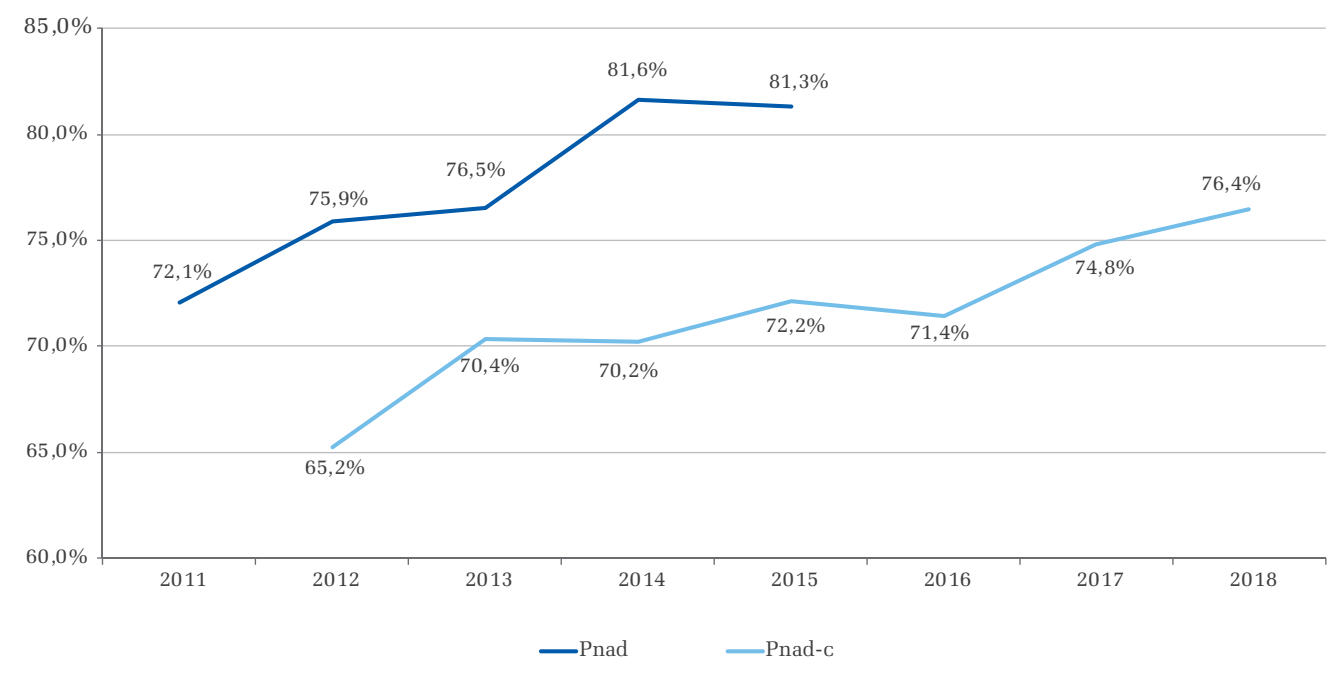

GRÁFICO 1

\section{COMPARAÇÃO ENTRE OS INDICADORES NACIONAIS DA META 17 DO PNE UTILIZANDO} DADOS DA PNAD E DA PNAD CONTÍNUA - 2011-2018 
Em 2012, o resultado para o indicador nacional da Meta 17, calculado com base nos dados da Pnad, registrou 75,9\%, enquanto o indicador medido com dados da Pnad Contínua anotou 10,7 p.p. a menos, perfazendo 65,2\%. Nos anos subsequentes, as diferenças perfizeram 6,1 p.p., em 2013, 11,4 p.p., em 2014 e 9,1 p.p., em 2015; sempre com os resultados do indicador da Pnad apresentando percentuais superiores aos registrados pela Pnad Contínua (ver Gráfico 1 e Tabela 3).

TABELA 3

\begin{abstract}
COMPARAÇÃO ENTRE O RENDIMENTO BRUTO MÉDIO MENSAL DOS PROFESSORES, DOS PROFISSIONAIS DO MAGISTÉRIO DAS REDES PÚBLICAS DA EDUCAÇÃO BÁSICA E DOS DEMAIS PROFISSIONAIS, CALCULADO COM BASE NOS DADOS DA PNAD E DA PNAD CONTÍNUA, E OS RESPECTIVOS INDICADORES DA META 17 DO PNE - BRASIL - 2011-2018
\end{abstract}

\begin{tabular}{|l|c|c|c|c|c|c|c|c|}
\hline \multicolumn{7}{|c|}{ DADOS DA PNAD } \\
\hline DESCRIÇÃO & 2011 & 2012 & 2013 & 2014 & 2015 & 2016 & 2017 & 2018 \\
\hline $\begin{array}{l}\text { Professores } \\
\text { Demais }\end{array}$ & $3.181,05$ & $3.301,74$ & $3.363,63$ & $3.531,33$ & $3.446,94$ & - & - & - \\
\hline $\begin{array}{l}\text { profissionais } \\
\text { Indicador 17 }\end{array}$ & $7.412,42$ & $4.351,46$ & $4.396,57$ & $4.324,98$ & $4.239,37$ & - & - & - \\
\hline & $72,1 \%$ & $75,9 \%$ & $76,5 \%$ & $81,6 \%$ & $81,3 \%$ & - & - & - \\
\hline
\end{tabular}

Profissionais do magistério

\begin{tabular}{|l|r|r|r|r|r|r|r|r|}
\hline $\begin{array}{l}\text { Demais } \\
\text { profissionais }\end{array}$ & - & $5.416,84$ & $5.291,35$ & $5.321,74$ & $5.311,40$ & $4.994,75$ & $4.816,14$ & $4.798,92$ \\
\hline Indicador 17 & - & $65,2 \%$ & $70,4 \%$ & $70,2 \%$ & $72,2 \%$ & $71,4 \%$ & $74,8 \%$ & $76,4 \%$ \\
\hline
\end{tabular}

Fonte: Elaboração própria com base em dados da Pnad/IBGE 2011-2015 e Pnad Contínua/IBGE 2012-2018 - 2º trimestre.

Nota: valores corrigidos pela variação do Índice de Nacional de Preços ao Consumidor Amplo - IPCA/IBGE, com preços de 2018.

Verificou-se que os rendimentos brutos médios mensais dos profissionais do magistério, mensurados pela Pnad, apresentaram valores inferiores aos registrados pela Pnad Contínua ao longo dos quatro anos em que as pesquisas foram coletadas simultaneamente (ver Tabela 3 e Gráfico 2). Esperava-se que os resultados da Pnad Contínua apresentassem valores mais elevados, uma vez que somente os profissionais do magistério com nível superior completo foram considerados na composição do numerador desse indicador. A maioria dos profissionais do magistério está empregada em ocupações de nível superior, que pagam remunerações superiores às ocupações de nível médio (no caso dos resultados da Pnad foram considerados os professores com pelo menos 12 anos de estudo, ou seja, há diversos casos de professores em ocupações de nível médio). 
A evolução dos valores reais dos rendimentos brutos médios mensais dos professores, calculados com dados da Pnad, indicou que houve ganhos no poder de compra durante o período em que as séries históricas se sobrepuseram, registrando aumento de 4,4\%, partindo de $\mathrm{R} \$ 3.301,74$, em 2012, para atingir $\mathrm{R} \$ 3.446,94$, em 2015 (ver Gráfico 2). Constatou-se que os resultados da Pnad apresentaram tendência de crescimento até o exercício de 2014, ano em que ocorreu o pico do poder de compra da série $(\mathrm{R} \$ 3.531,33)$.

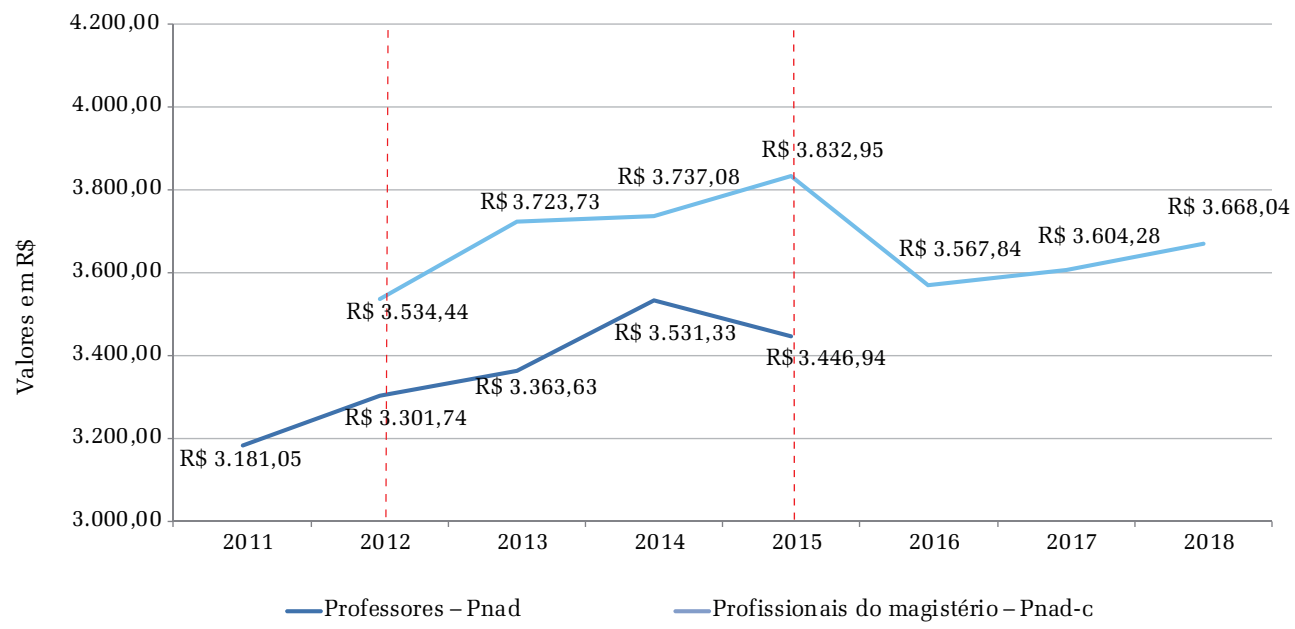

GRÁFICO 2

COMPARAÇÃO ENTRE OS RENDIMENTOS BRUTOS MÉDIOS MENSAIS REAIS DOS PROFESSORES E DOS PROFISSIONAIS DO MAGISTÉRIO DA EDUCAÇÃO BÁSICA, COM BASE NA PNAD E NA PNAD CONTÍNUA - 2011-2018 - BRASIL

Fonte: Elaboração própria com base em dados da Pnad/IBGE 2011-2015 e Pnad Contínua/IBGE 2012-2018 - 2 trimestre.

Já os resultados dos rendimentos brutos médios mensais reais dos profissionais do magistério calculados com base nos dados da Pnad Contínua, para o mesmo período, acusaram crescimento de 8,4\%, prosperando de $\mathrm{R} \$ 3.534,44$, em 2012, para $\mathrm{R} \$ 3.832,95$, em 2015 (ver Gráfico 2). No caso da Pnad Contínua, os resultados evidenciaram o pico da série no ano de 2015. O resultado do exercício de 2016 apresentou retração de $-6,9 \%$, registrando R $\$ 3.567,84$ e, no biênio subsequente, houve pequena recuperação no poder de compra do rendimento médio dos profissionais do magistério, alcançando $\mathrm{R} \$ 3.668,04$ em 2018 (crescimento 2,8\% em relação ao ano de 2016).

Na Tabela 4, apresentou-se o quantitativo de observações que foram selecionadas para compor o grupo de professores e de profissionais do magistério e suas respectivas expansões com base nos dados da Pnad e da Pnad Contínua. A quantidade de observações de professores da educação básica pública coletadas nas bases da Pnad Contínua é superior, entre $27 \%$ e $37 \%$, às coletadas na base da Pnad (no período 
de 2012 a 2015). Cabe salientar que os dados da Pnad Contínua incluem os professores das redes federais, enquanto os resultados da Pnad consideraram apenas os professores das redes estaduais, municipais e distrital. Sendo assim, o parâmetro de escolha para as observações na Pnad Contínua é mais abrangente do que o critério arbitrado para a seleção na Pnad. Ainda, ao incluir os outros profissionais do magistério, ou seja, todas as ocupações referentes aos profissionais do ensino listados no COD, a quantidade de observações coletadas na Pnad Contínua passa a ser superior, entre $44 \%$ e 58\%, às coletadas na Pnad. Portanto, a Pnad Contínua apresenta cobertura estatisticamente mais representativa e, consequentemente, retrata de forma mais fidedigna a realidade do mercado de trabalho e os rendimentos médios auferidos por essas categorias profissionais (ver Tabela 4).

TABELA 4

COMPARATIVO ENTRE O QUANTITATIVO DE OBSERVAÇÕES SELECIONADAS DE PROFESSORES E SUA EXPANSÃO, COM BASE NOS DADOS DA PNAD, E O QUANTITATIVO DE OBSERVAÇÕES SELECIONADAS DE PROFESSORES, PROFISSIONAIS DO MAGISTÉRIO E SUAS EXPANSÕES, COM BASE NOS DADOS DA PNAD CONTÍNUA - BRASIL - 2011-2018

\begin{tabular}{|c|c|c|c|c|c|c|c|c|}
\hline \multicolumn{9}{|c|}{ DADOS DA PNAD } \\
\hline DESCRIÇÃO & 2011 & 2012 & 2013 & 2014 & 2015 & 2016 & 2017 & 2018 \\
\hline $\begin{array}{l}\text { Amostra de } \\
\text { professores }\end{array}$ & 3.352 & 3.437 & 3.580 & 3.749 & 3.610 & - & - & - \\
\hline $\begin{array}{l}\text { Expansão de } \\
\text { professores }\end{array}$ & 1.841 .122 & 1.884 .140 & 2.025 .385 & 2.123 .247 & 2.084 .963 & - & - & - \\
\hline \multicolumn{9}{|c|}{ DADOS DA PNAD CONTÍNUA } \\
\hline $\begin{array}{l}\text { Amostra de } \\
\text { professores }\end{array}$ & - & 4.540 & 4.550 & 4.793 & 4.964 & 5.125 & 5.173 & 5.335 \\
\hline $\begin{array}{l}\text { Expansão de } \\
\text { professores }\end{array}$ & - & 1.652 .423 & 1.670 .897 & 1.715 .761 & 1.767 .574 & 1.808 .729 & 1.881 .232 & 1.939 .441 \\
\hline $\begin{array}{l}\text { Amostra de } \\
\text { profissionais } \\
\text { do } \\
\text { magistério }\end{array}$ & - & 5.126 & 5.156 & 5.393 & 5.705 & 5.598 & 5.616 & 5.882 \\
\hline $\begin{array}{l}\text { Expansão de } \\
\text { profissionais } \\
\text { do } \\
\text { magistério }\end{array}$ & - & 1.865 .555 & 1.898 .117 & 1.919 .494 & 2.020 .118 & 1.976 .538 & 2.028 .758 & 2.144 .616 \\
\hline
\end{tabular}

Fonte: Elaboração própria com base em dados da Pnad/IBGE 2011-2015 e Pnad Contínua/IBGE 2012-2018 - 2º trimestre. 
No que diz respeito aos valores reais dos rendimentos brutos médios mensais dos "demais profissionais", observou-se que, ao longo do período em que as séries históricas se sobrepuseram, os resultados da Pnad e da Pnad Contínua apresentaram tendência semelhante: perda de poder de compra. No caso dos resultados da Pnad, a perda de poder de compra se mostrou pouco mais acentuada, com recuo de $-2,6 \%$, caindo de $\mathrm{R} \$ 4.351,46$, em 2012, para $\mathrm{R} \$ 4.239,37$, em 2015. Já os resultados da Pnad Contínua registraram queda de $-1,9 \%$ no mesmo período, denotando retração de $\mathrm{R} \$ 5.416,84$, em 2012, para R\$5.311,40, em 2015 (ver Gráfico 3).

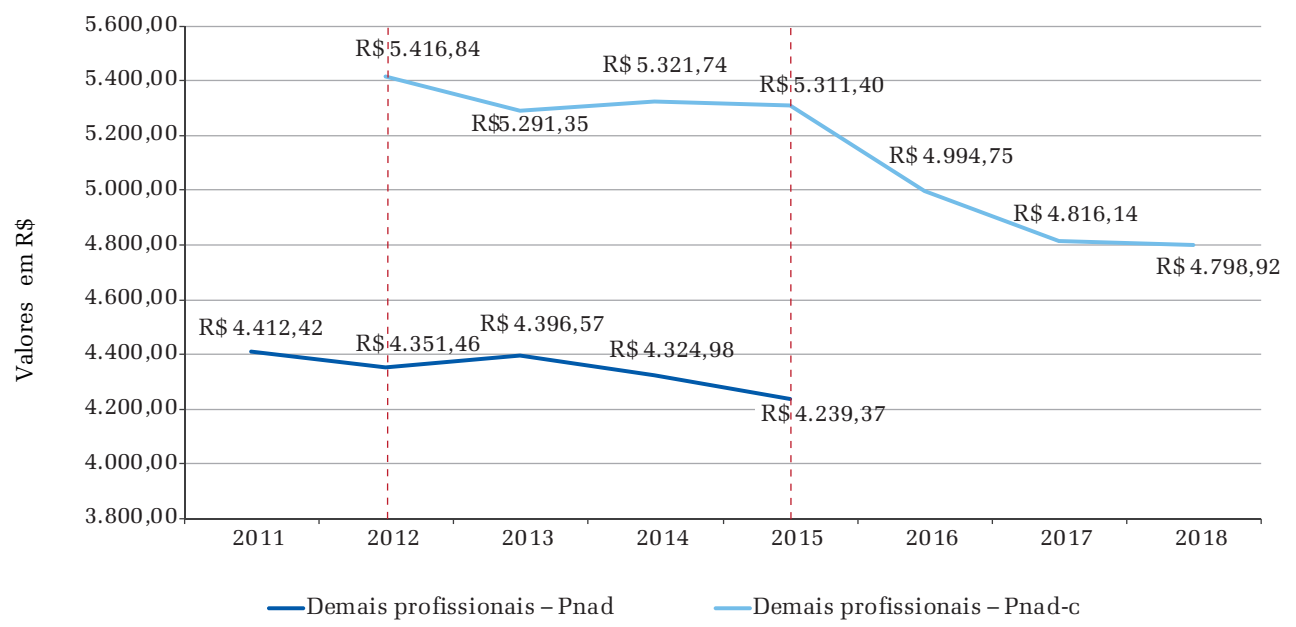

\section{GRÁFICO 3 \\ COMPARAÇÃO ENTRE OS RENDIMENTOS BRUTOS MÉDIOS MENSAIS REAIS DOS DEMAIS PROFISSIONAIS, COM BASE NA PNAD E NA PNAD CONTÍNUA - 2011-2018 - BRASIL}

Fonte: Elaboração própria com base em dados da Pnad/IBGE 2011-2015 e Pnad Contínua/IBGE 2012-2018 - $2^{\circ}$ trimestre.

Dentre os motivos de os valores dos rendimentos brutos médios mensais reais dos demais profissionais serem mais elevados na Pnad Contínua do que na Pnad estão os parâmetros arbitrados nas escolhas metodológicas da construção de cada indicador. No caso da Pnad Contínua, isso se deve em grande parte à adoção do critério de corte, na cauda inferior da distribuição, dos rendimentos com valores abaixo do salário mínimo nacional do respectivo exercício. Assim, com a exclusão dos baixos rendimentos, os valores médios obtidos com dados da Pnad Contínua se apresentaram mais elevados do que os da Pnad. Isso ocorre uma vez que, na metodologia utilizada para a produção do indicador baseado na Pnad, não foi adotado nenhum critério de exclusão dos baixos valores (inferiores ao salário mínimo nacional), o que fez com que as médias dos rendimentos brutos mensais tendessem a ser menores. 


\section{CONSIDERAÇÕES FINAIS}

De modo geral, este artigo objetivou tornar públicas as diferenças metodológicas existentes entre os indicadores dos relatórios técnicos publicados pelo Inep, visando o acompanhamento e o monitoramento da Meta 17 do PNE. Foram descritas e comparadas as metodologias adotadas para a construção dos indicadores, tendo como base os dados das pesquisas domiciliares publicadas pelo IBGE: a Pnad e a Pnad Contínua. Ainda, foram analisados e comparados os resultados obtidos por meio da aplicação das metodologias em suas respectivas bases de dados.

O indicador nacional da Meta 17 do PNE, calculado com base nos dados da Pnad, registrou resultados percentuais superiores aos registrados pela Pnad Contínua ao longo dos quatro exercícios em que ambas as pesquisas foram realizadas concomitantemente (2012-2015). Todavia, durante o mesmo período, os rendimentos brutos médios mensais mensurados pela Pnad, tanto para os profissionais do magistério da educação básica como para os demais profissionais, apresentaram valores reais inferiores aos observados pela Pnad Contínua.

Ficou evidente que parte das diferenças encontradas nos resultados dos indicadores da Meta 17 se deu em razão do delineamento metodológico adotado pelas próprias pesquisas domiciliares do IBGE, sobretudo no que diz respeito a parâmetros como: abrangência geográfica, plano amostral, tamanho da amostra e periodicidade da coleta.

Mudanças nos procedimentos metodológicos arbitrados para a construção do indicador da Pnad Contínua também foram responsáveis pelas diferenças observadas nos resultados em relação ao indicador da Pnad. As alterações implementadas no indicador calculado com base nos dados da Pnad Contínua foram: mudança da variável "escolaridade", modificações na seleção das categorias das variáveis "ocupação" e "redes de ensino" e inclusão da variável proxy para "posição no trabalho" no cálculo do denominador. Tais aperfeiçoamentos metodológicos foram adotados visando atender precipuamente aos condicionantes legais impostos pelo caput da Meta 17 da Lei $n^{0}$ 13.005/14.

\section{REFERÊNCIAS}

ALVES, T.; SONOBE, A. K. Remuneração média como indicador da valorização docente no mercado de trabalho. Cadernos de Pesquisa, São Paulo, v. 48, n. 168, p. 446-476, abr./jun. 2018.

BRASIL. Constituição (1988). Constituição da República Federativa do Brasil de 1988. Brasília, DF: Senado Federal, 1988. 
BRASIL. Lei $\mathrm{n}^{\circ}$ 9.394, de 20 de dezembro de 1996. Estabelece as diretrizes e bases da educação nacional. Diário Oficial da União, Brasília, DF, 23 dez. 1996. Seção 1, p. 27833.

BRASIL. Lei no 11.738, de 16 de julho de 2008. Regulamenta a alínea "e" do inciso III do caput do art. 60 do Ato das Disposições Constitucionais Transitórias, para instituir o piso salarial profissional nacional para os profissionais do magistério público da educação básica. Diário Oficial da União, Brasília, DF, 17 jul. 2008, Seção 1, p. 1.

BRASIL. Lei $\mathrm{n}^{\mathrm{O}}$ 13.005, de 25 de junho de 2014. Aprova o Plano Nacional de Educação - PNE e dá outras providências. Diário Oficial da União, Brasília, DF, 26 jun. 2014, Seção 1, p. 1.

BRASIL. Instituto Nacional de Estudos e Pesquisas Educacionais Anísio Teixeira (Inep). Plano Nacional de Educação PNE 2014-2024: linha de base. Brasília, 2015.

BRASIL. Instituto Nacional de Estudos e Pesquisas Educacionais Anísio Teixeira (Inep). Relatório do $1^{\circ}$ ciclo de monitoramento das metas do PNE: biênio 2014-2016. Brasília, DF: Inep, 2016.

BRASIL. Instituto Nacional de Estudos e Pesquisas Educacionais Anísio Teixeira (Inep). Relatório do $2^{\circ}$ ciclo de monitoramento das metas do Plano Nacional de Educação - 2018. Brasília, 2018.

BRITO, A. M.; WALTENBERG, F. D. É atrativo tornar-se professor do ensino médio no Brasil? evidências com base em decomposições paramétricas e não paramétricas. Estudos Econômicos, São Paulo, v. 44, n. 1, p. 5-44, jan./mar. 2014.

\section{DEPARTAMENTO INTERSINDICAL DE ESTATÍSTICA E ESTUDOS} SOCIOECONÔMICOS (Dieese) Transformações recentes no perfil do docente das escolas estaduais e municipais de educação básica. São Paulo: Dieese, 2014. (Nota técnica, n. 141).

FAVERO, L.; BELFIORE, P. Manual de análise de dados: estatística e modelagem multivariada com Excel®, SPSS® e Stata ${ }^{\circledR}$. Rio de Janeiro: Elservier, 2017.

INSTITUTO BRASILEIRO DE GEOGRAFIA E ESTATÍSTICA (IBGE). Estudos e tratamento da variável rendimento no Censo Demográfico 2010. Rio de Janeiro, 2012. Disponível em: <ftp://ftp.ibge.gov.br/Censos/Censo_Demografico_2010/Resultados_ Gerais_da_Amostra/Estudo_e_tratamento_rendimentos.pdf $>$. Acesso em: 01 ago. 2018. 


\section{INSTITUTO BRASILEIRO DE GEOGRAFIA E ESTATÍSTICA (IBGE). Pesquisa}

Nacional por Amostra de Domicílios Contínua: notas metodológicas. Rio de Janeiro, 2014. Disponível em: <ftp:/ftp.ibge.gov.br/Trabalho_e_Rendimento/Pesquisa_ Nacional_por_Amostra_de_Domicilios_continua/Notas_metodologicas/notas_ metodologicas.pdf > . Acesso em: 06 ago. 2018.

INSTITUTO BRASILEIRO DE GEOGRAFIA E ESTATÍSTICA (IBGE). Dicionário de variáveis da Pnad 2015: arquivo de pessoas: microdados das pesquisas básica e suplementar de acesso à internet e à televisão. Rio de Janeiro, 2015. Disponível em: <https://ww2.ibge.gov.br/home/estatistica/populacao/trabalhoerendimento/ pnad2015/microdados.shtm>. Acesso em: 16 jul. 2018.

INSTITUTO BRASILEIRO DE GEOGRAFIA E ESTATÍSTICA (IBGE). Dicionário das variáveis da PNAD contínua: $1^{\mathrm{a}}$ visita com parte de características gerais dos moradores, rendimentos de outras fontes e habitação: 2017. Rio de Janeiro, 2017. Disponível em: <ftp://ftp.ibge.gov.br/Trabalho_e_Rendimento/Pesquisa_Nacional_ por_Amostra_de_Domicilios_continua/Anual/Microdados/Documentacao/dicionario_ PNAD_CONTINUA_MICRODADOS_1_visita_2017_20190516.xls >. Acesso em: 23 jul. 2018.

INSTITUTO BRASILEIRO DE GEORAFIA E ESTATÍSTICA (IBGE). Pesquisa Nacional por Amostra de Domicílios Contínua: notas técnicas: versão 1.5. Rio de Janeiro, 2018. Disponível em: <https://biblioteca.ibge.gov.br/visualizacao/livros/liv101561_ notas_tecnicas.pdf $>$. Acesso em: 06 ago. 2018.

JACOMINI, M. A.; ALVES, T.; CAMARGO, R. B. de. Remuneração docente: desafios para o monitoramento da valorização dos professores brasileiros no contexto da Meta 17 do Plano Nacional de Educação. Archivos Analíticos de Políticas Educativas / Education Policy Analysis Archives, Arizona, v. 24, p. 1-35, 2016.

JANNUZZI, P. M. Indicadores para diagnóstico, monitoramento e avaliação de programas sociais no Brasil. Revista do Serviço Público, Brasília, v. 56, n. 2, p. 137-160, abr./jun. 2005.

MORICONI, G. M. Os professores públicos são mal remunerados nas escolas brasileiras? uma análise da atratividade da carreira do magistério sob o aspecto da remuneração. São Paulo: Fundação Getúlio Vargas, 2008.

ORGANISATION FOR ECONOMIC COOPERATION AND DEVELOPMENT (OECD). Education at a glance 2017: OECD indicators, Paris: OECD Publishing, 2017. Disponível em: <http://dx.doi.org/10.1787/eag-2017-en>. Acesso em: 30 jul. 2018. TODOS PELA EDUCAÇÃO. Anuário brasileiro da educação básica. São Paulo: Moderna, 2015. 


\section{YAPÊNDICES}

\begin{tabular}{|c|c|c|c|c|c|c|}
\hline \multicolumn{7}{|c|}{ APÊNDICE A } \\
\hline \multicolumn{7}{|c|}{ RENDIMENTO BRUTO MÉDIO MENSAL DOS PROFESSORES DAS REDES PÚBLICAS } \\
\hline \multicolumn{7}{|c|}{ DA EDUCAÇÃO BÁSICA E DOS DEMAIS PROFISSIONAIS, CALCULADOS COM BASE NOS } \\
\hline \multicolumn{7}{|c|}{ DADOS DA PNAD, E OS RESPECTIVOS INDICADORES DA META 17 - BRASIL - 2011-2015 } \\
\hline \multirow{3}{*}{ UF } & \multirow{3}{*}{ DESCRIÇÃO } & \multicolumn{5}{|c|}{ ANO } \\
\hline & & & & & & \\
\hline & & 2011 & 2012 & 2013 & 2014 & 2015 \\
\hline \multirow{3}{*}{$\mathrm{RO}$} & Professores & $2.789,24$ & $2.864,41$ & $3.078,26$ & $2.821,94$ & $3.089,37$ \\
\hline & $\begin{array}{l}\text { Demais } \\
\text { profissionais }\end{array}$ & $3.562,66$ & $3.447,48$ & $3.495,57$ & $3.654,85$ & $3.288,45$ \\
\hline & Indicador & $78,3 \%$ & $83,1 \%$ & $88,1 \%$ & $77,2 \%$ & $93,9 \%$ \\
\hline \multirow{3}{*}{$\mathrm{AC}$} & Professores & $3.639,85$ & $4.045,50$ & $3.712,82$ & $3.678,66$ & $3.472,79$ \\
\hline & $\begin{array}{l}\text { Demais } \\
\text { profissionais }\end{array}$ & $3.845,83$ & $3.404,05$ & $3.289,09$ & $3.650,06$ & $3.677,67$ \\
\hline & Indicador & $94,6 \%$ & $118,8 \%$ & $112,9 \%$ & $100,8 \%$ & $94,4 \%$ \\
\hline \multirow{3}{*}{$\mathrm{AM}$} & Professores & $2.796,41$ & $2.926,18$ & $2.946,83$ & $3.176,89$ & $3.406,56$ \\
\hline & $\begin{array}{l}\text { Demais } \\
\text { profissionais }\end{array}$ & $4.054,21$ & $3.357,05$ & $3.538,52$ & $3.787,32$ & $3.592,48$ \\
\hline & Indicador & $69,0 \%$ & $87,2 \%$ & $83,3 \%$ & $83,9 \%$ & $94,8 \%$ \\
\hline \multirow{3}{*}{$\mathrm{RR}$} & Professores & $4.719,46$ & $5.228,10$ & $3.651,47$ & $5.817,15$ & $5.321,92$ \\
\hline & $\begin{array}{l}\text { Demais } \\
\text { profissionais }\end{array}$ & $3.360,52$ & $3.376,33$ & $3.714,90$ & $3.771,80$ & $3.649,22$ \\
\hline & Indicador & $140,4 \%$ & $154,8 \%$ & $98,3 \%$ & $154,2 \%$ & $145,8 \%$ \\
\hline \multirow{3}{*}{$\mathrm{PA}$} & Professores & $2.842,06$ & $2.895,61$ & $3.111,72$ & $3.254,70$ & $3.327,03$ \\
\hline & $\begin{array}{l}\text { Demais } \\
\text { profissionais }\end{array}$ & $3.764,90$ & $3.654,98$ & $3.603,36$ & $3.577,03$ & $3.360,52$ \\
\hline & Indicador & $75,5 \%$ & $79,2 \%$ & $86,4 \%$ & $91,0 \%$ & $99,0 \%$ \\
\hline \multirow{3}{*}{$\mathrm{AP}$} & Professores & $3.753,43$ & $4.670,43$ & $4.578,14$ & $4.312,15$ & $4.134,70$ \\
\hline & $\begin{array}{l}\text { Demais } \\
\text { profissionais }\end{array}$ & $2.928,70$ & $4.298,32$ & $3.890,04$ & $3.611,10$ & $3.486,90$ \\
\hline & Indicador & $128,2 \%$ & $108,7 \%$ & $117,7 \%$ & $119,4 \%$ & $118,6 \%$ \\
\hline
\end{tabular}




\section{APÊNDICE A}

\section{RENDIMENTO BRUTO MÉDIO MENSAL DOS PROFESSORES DAS REDES PÚBLICAS DA EDUCAÇÃO BÁSICA E DOS DEMAIS PROFISSIONAIS, CALCULADOS COM BASE NOS DADOS DA PNAD, E OS RESPECTIVOS INDICADORES DA META 17 - BRASIL - 2011-2015}

(continuação)

\begin{tabular}{|c|c|c|c|c|c|c|}
\hline \multirow{2}{*}{ UF } & \multirow{2}{*}{ DESCRIÇÃO } & \multicolumn{5}{|c|}{ ANO } \\
\hline & & 2011 & 2012 & 2013 & 2014 & 2015 \\
\hline \multirow{3}{*}{ TO } & Professores & $3.298,68$ & $3.457,05$ & $3.125,63$ & $3.153,05$ & $2.967,96$ \\
\hline & $\begin{array}{l}\text { Demais } \\
\text { profissionais }\end{array}$ & $3.539,74$ & $3.432,62$ & $4.322,75$ & $3.688,68$ & $4.188,90$ \\
\hline & Indicador & $93,2 \%$ & $100,7 \%$ & $72,3 \%$ & $85,5 \%$ & $70,9 \%$ \\
\hline \multirow{3}{*}{ MA } & Professores & $2.587,17$ & $3.103,69$ & $3.509,11$ & $3.382,47$ & $3.441,15$ \\
\hline & $\begin{array}{l}\text { Demais } \\
\text { profissionais }\end{array}$ & $3.979,59$ & $4.061,78$ & $3.911,51$ & $3.210,38$ & $3.767,45$ \\
\hline & Indicador & $65,0 \%$ & $76,4 \%$ & $89,7 \%$ & $105,4 \%$ & $91,3 \%$ \\
\hline \multirow{3}{*}{ PI } & Professores & $2.283,81$ & $2.623,21$ & $2.931,78$ & $2.510,39$ & $2.968,36$ \\
\hline & $\begin{array}{l}\text { Demais } \\
\text { profissionais }\end{array}$ & $2.983,15$ & $3.247,63$ & $3.342,35$ & $3.157,85$ & $3.061,73$ \\
\hline & Indicador & $76,6 \%$ & $80,8 \%$ & $87,7 \%$ & $79,5 \%$ & $97,0 \%$ \\
\hline \multirow{3}{*}{$\mathrm{CE}$} & Professores & $2.379,45$ & $2.477,71$ & $2.427,89$ & $2.681,31$ & $2.635,41$ \\
\hline & $\begin{array}{l}\text { Demais } \\
\text { profissionais }\end{array}$ & $3.325,90$ & $3.680,31$ & $3.122,52$ & $3.233,17$ & $2.926,53$ \\
\hline & Indicador & $71,5 \%$ & $67,3 \%$ & $77,8 \%$ & $82,9 \%$ & $90,1 \%$ \\
\hline \multirow{3}{*}{$\mathrm{RN}$} & Professores & $2.330,04$ & $3.170,14$ & $3.110,51$ & $2.957,19$ & $3.063,33$ \\
\hline & $\begin{array}{l}\text { Demais } \\
\text { profissionais }\end{array}$ & $4.155,19$ & $3.475,31$ & $4.174,30$ & $3.609,17$ & $3.548,95$ \\
\hline & Indicador & $56,1 \%$ & $91,2 \%$ & $74,5 \%$ & $81,9 \%$ & $86,3 \%$ \\
\hline \multirow{3}{*}{$\mathrm{PB}$} & Professores & $2.714,10$ & $2.482,24$ & $2.917,80$ & $3.016,16$ & $3.158,63$ \\
\hline & $\begin{array}{l}\text { Demais } \\
\text { profissionais }\end{array}$ & $3.779,38$ & $3.522,75$ & $3.204,59$ & $3.291,30$ & $3.612,40$ \\
\hline & Indicador & $71,8 \%$ & $70,5 \%$ & $91,1 \%$ & $91,6 \%$ & $87,4 \%$ \\
\hline \multirow{3}{*}{$\mathrm{PE}$} & Professores & $2.579,20$ & $2.629,70$ & $2.796,18$ & $3.028,83$ & $2.771,91$ \\
\hline & $\begin{array}{l}\text { Demais } \\
\text { profissionais }\end{array}$ & $3.592,74$ & $3.502,15$ & $3.248,87$ & $3.342,41$ & $3.018,50$ \\
\hline & Indicador & $71,8 \%$ & $75,1 \%$ & $86,1 \%$ & $90,6 \%$ & $91,8 \%$ \\
\hline \multirow{3}{*}{$\mathrm{AL}$} & Professores & $2.726,19$ & $2.907,58$ & $3.283,89$ & $2.982,33$ & $3.223,14$ \\
\hline & $\begin{array}{l}\text { Demais } \\
\text { profissionais }\end{array}$ & $3.372,67$ & $3.020,79$ & $3.749,04$ & $3.147,83$ & $3.155,47$ \\
\hline & Indicador & $80,8 \%$ & $96,3 \%$ & $87,6 \%$ & $94,7 \%$ & $102,1 \%$ \\
\hline
\end{tabular}




\section{APÊNDICE A}

\section{RENDIMENTO BRUTO MÉDIO MENSAL DOS PROFESSORES DAS REDES PÚBLICAS DA EDUCAÇÃO BÁSICA E DOS DEMAIS PROFISSIONAIS, CALCULADOS COM BASE NOS DADOS DA PNAD, E OS RESPECTIVOS INDICADORES DA META 17 - BRASIL - 2011-2015}

(continuação)

\begin{tabular}{|c|c|c|c|c|c|c|}
\hline \multirow{2}{*}{ UF } & \multirow{2}{*}{ DESCRIÇÃO } & \multicolumn{5}{|c|}{ ANO } \\
\hline & & 2011 & 2012 & 2013 & 2014 & 2015 \\
\hline \multirow{3}{*}{ SE } & Professores & $4.479,76$ & $4.229,28$ & $4.045,68$ & $4.072,48$ & $5.000,71$ \\
\hline & $\begin{array}{l}\text { Demais } \\
\text { profissionais }\end{array}$ & $4.039,26$ & $3.943,70$ & $4.134,31$ & $3.079,18$ & $2.965,68$ \\
\hline & Indicador & $110,9 \%$ & $107,2 \%$ & $97,9 \%$ & $132,3 \%$ & $168,6 \%$ \\
\hline \multirow{3}{*}{ BA } & Professores & $2.780,87$ & $2.867,63$ & $3.217,63$ & $3.183,95$ & $3.128,05$ \\
\hline & $\begin{array}{l}\text { Demais } \\
\text { profissionais }\end{array}$ & $4.124,46$ & $4.102,66$ & $4.117,45$ & $3.831,93$ & $3.159,79$ \\
\hline & Indicador & $67,4 \%$ & $69,9 \%$ & $78,1 \%$ & $83,1 \%$ & $99,0 \%$ \\
\hline \multirow{3}{*}{ MG } & Professores & $2.916,28$ & $3.193,22$ & $3.196,17$ & $3.220,29$ & $3.299,20$ \\
\hline & $\begin{array}{l}\text { Demais } \\
\text { profissionais }\end{array}$ & $4.001,32$ & $4.160,01$ & $4.045,37$ & $3.970,27$ & $4.037,01$ \\
\hline & Indicador & $72,9 \%$ & $76,8 \%$ & $79,0 \%$ & $81,1 \%$ & $81,7 \%$ \\
\hline \multirow{3}{*}{ ES } & Professores & $3.278,85$ & $3.648,35$ & $3.194,90$ & $3.556,88$ & $3.574,82$ \\
\hline & $\begin{array}{l}\text { Demais } \\
\text { profissionais }\end{array}$ & $3.833,16$ & $4.100,66$ & $3.839,66$ & $4.079,42$ & $3.788,05$ \\
\hline & Indicador & $85,5 \%$ & $89,0 \%$ & $83,2 \%$ & $87,2 \%$ & $94,4 \%$ \\
\hline \multirow{3}{*}{ RJ } & Professores & $4.389,62$ & $4.144,37$ & $4.004,71$ & $4.474,06$ & $3.975,96$ \\
\hline & $\begin{array}{l}\text { Demais } \\
\text { profissionais }\end{array}$ & $5.484,83$ & $4.978,75$ & $5.201,80$ & $5.071,17$ & $5.027,40$ \\
\hline & Indicador & $80,0 \%$ & $83,2 \%$ & $77,0 \%$ & $88,2 \%$ & $79,1 \%$ \\
\hline \multirow{3}{*}{ SP } & Professores & $3.395,04$ & $3.384,39$ & $3.304,36$ & $3.739,12$ & $3.429,96$ \\
\hline & $\begin{array}{l}\text { Demais } \\
\text { profissionais }\end{array}$ & $4.665,20$ & $4.628,72$ & $4.784,41$ & $4.751,17$ & $4.657,71$ \\
\hline & Indicador & $72,8 \%$ & $73,1 \%$ & $69,1 \%$ & $78,7 \%$ & $73,6 \%$ \\
\hline \multirow{3}{*}{ PR } & Professores & $3.500,46$ & $3.593,64$ & $3.716,99$ & $4.059,80$ & $3.965,50$ \\
\hline & $\begin{array}{l}\text { Demais } \\
\text { profissionais }\end{array}$ & $3.785,43$ & $4.062,11$ & $4.137,38$ & $4.054,96$ & $4.193,46$ \\
\hline & Indicador & $92,5 \%$ & $88,5 \%$ & $89,8 \%$ & $100,1 \%$ & $94,6 \%$ \\
\hline \multirow{3}{*}{ SC } & Professores & $2.683,88$ & $3.074,71$ & $3.189,98$ & $3.243,60$ & $3.227,60$ \\
\hline & $\begin{array}{l}\text { Demais } \\
\text { profissionais }\end{array}$ & $4.040,20$ & $3.590,92$ & $3.622,22$ & $3.748,60$ & $3.919,55$ \\
\hline & Indicador & $66,4 \%$ & $85,6 \%$ & $88,1 \%$ & $86,5 \%$ & $82,3 \%$ \\
\hline
\end{tabular}




\section{APÊNDICE A}

\section{RENDIMENTO BRUTO MÉDIO MENSAL DOS PROFESSORES DAS REDES PÚBLICAS DA EDUCAÇÃO BÁSICA E DOS DEMAIS PROFISSIONAIS, CALCULADOS COM BASE NOS DADOS DA PNAD, E OS RESPECTIVOS INDICADORES DA META 17 - BRASIL - 2011-2015}

(conclusão)

\begin{tabular}{|c|c|c|c|c|c|c|}
\hline \multirow{2}{*}{ UF } & \multirow{2}{*}{ DESCRIÇÃO } & \multicolumn{5}{|c|}{ ANO } \\
\hline & & 2011 & 2012 & 2013 & 2014 & 2015 \\
\hline \multirow{3}{*}{ RS } & Professores & $3.200,58$ & $3.463,55$ & $3.608,53$ & $3.734,15$ & $3.548,07$ \\
\hline & $\begin{array}{l}\text { Demais } \\
\text { profissionais }\end{array}$ & $4.248,52$ & $4.116,37$ & $4.327,61$ & $4.242,55$ & $4.178,65$ \\
\hline & Indicador & $75,3 \%$ & $84,1 \%$ & $83,4 \%$ & $88,0 \%$ & $84,9 \%$ \\
\hline \multirow{3}{*}{ MS } & Professores & $3.760,88$ & $3.664,99$ & $4.256,05$ & $4.278,29$ & $4.510,79$ \\
\hline & $\begin{array}{l}\text { Demais } \\
\text { profissionais }\end{array}$ & $4.729,19$ & $4.318,93$ & $4.344,25$ & $3.758,18$ & $4.207,68$ \\
\hline & Indicador & $79,5 \%$ & $84,9 \%$ & $98,0 \%$ & $113,8 \%$ & $107,2 \%$ \\
\hline \multirow{3}{*}{ MT } & Professores & $3.498,51$ & $3.430,65$ & $3.422,27$ & $3.443,66$ & $3.772,97$ \\
\hline & $\begin{array}{l}\text { Demais } \\
\text { profissionais }\end{array}$ & $3.731,58$ & $4.706,44$ & $4.252,58$ & $4.021,17$ & $3.692,29$ \\
\hline & Indicador & $93,8 \%$ & $72,9 \%$ & $80,5 \%$ & $85,6 \%$ & $102,2 \%$ \\
\hline \multirow{3}{*}{$\mathrm{GO}$} & Professores & $3.023,47$ & $2.982,15$ & $3.392,94$ & $3.302,88$ & $3.271,09$ \\
\hline & $\begin{array}{l}\text { Demais } \\
\text { profissionais }\end{array}$ & $3.771,50$ & $3.745,65$ & $3.295,46$ & $3.281,46$ & $3.174,81$ \\
\hline & Indicador & $80,2 \%$ & $79,6 \%$ & $103,0 \%$ & $100,7 \%$ & $103,0 \%$ \\
\hline \multirow{3}{*}{$\mathrm{DF}$} & Professores & $6.116,93$ & $6.667,86$ & $7.256,54$ & $6.918,00$ & $6.248,99$ \\
\hline & $\begin{array}{l}\text { Demais } \\
\text { profissionais }\end{array}$ & $7.433,29$ & $7.910,10$ & $7.853,65$ & $7.810,85$ & $7.698,39$ \\
\hline & Indicador & $82,3 \%$ & $84,3 \%$ & $92,4 \%$ & $88,6 \%$ & $81,2 \%$ \\
\hline
\end{tabular}

Fonte: Elaboração própria com base em dados da Pnad/IBGE 2011-2015.

Nota: valores corrigidos pela variação do IPCA/IBGE, com preços de 2018. 


\begin{tabular}{|c|c|c|c|c|c|c|c|c|}
\hline & & & & NDICE B & & & & \\
\hline & NDIMENTO & JTO MI & MENS & L DOS PRC & OFISSIO & AIS DO N & GISTÉR & DAS \\
\hline & ; PÚBLICAS & EDUCA & O BÁSIC & E DOS DI & EMAIS PR & OFISSION & AIS, CALC & ULADOS \\
\hline & BASE NO & $\cos \mathrm{D}$ & NAD CON & ríNUA, E & OS RESPE & CTIVOS I & DICAD & ES DA \\
\hline & & & IETA 17 - & RASIL - 2 & 012-2018 & & & con \\
\hline & & & & & ANO & & & \\
\hline & & 2012 & 2013 & 2014 & 2015 & 2016 & 2017 & 2018 \\
\hline & $\begin{array}{l}\text { Profissionais } \\
\text { do magistério }\end{array}$ & $3.217,43$ & $3.102,18$ & $3.159,81$ & $3.364,74$ & $3.010,95$ & $3.070,34$ & $3.268,13$ \\
\hline $\mathrm{RO}$ & $\begin{array}{l}\text { Demais } \\
\text { profissionais }\end{array}$ & $5.365,87$ & $5.028,27$ & $4.155,49$ & $4.206,98$ & $3.819,61$ & $4.208,30$ & $4.297,42$ \\
\hline & Indicador & $60,0 \%$ & $61,7 \%$ & $76,0 \%$ & $80,0 \%$ & $78,8 \%$ & $73,0 \%$ & $76,0 \%$ \\
\hline & $\begin{array}{l}\text { Profissionais } \\
\text { do magistério }\end{array}$ & $4.158,92$ & $4.346,64$ & $4.313,03$ & $4.732,20$ & $3.565,10$ & $3.570,72$ & $3.762,50$ \\
\hline AC & $\begin{array}{l}\text { Demais } \\
\text { profissionais }\end{array}$ & $5.385,90$ & $5.145,20$ & $5.078,53$ & $5.142,69$ & $4.478,24$ & $4.832,68$ & $4.397,00$ \\
\hline & Indicador & $77,2 \%$ & $\%$ & $84,9 \%$ & $92,0 \%$ & $79,6 \%$ & $73,9 \%$ & $85,6 \%$ \\
\hline & $\begin{array}{l}\text { Profissionais } \\
\text { do magistério }\end{array}$ & $3.339,95$ & $3.137,71$ & $3.388,21$ & $3.319,47$ & $2.985,62$ & $3.273,98$ & $3.642,73$ \\
\hline AM & $\begin{array}{l}\text { Demais } \\
\text { profissionais }\end{array}$ & $5.486,77$ & $6.197,80$ & $5.547,01$ & $5.766,06$ & $5.130,33$ & $5.360,14$ & $4.719,22$ \\
\hline & Indicador & $60,9 \%$ & $0,6 \%$ & $61,1 \%$ & $57,6 \%$ & $58,2 \%$ & $61,1 \%$ & $77,2 \%$ \\
\hline & $\begin{array}{l}\text { Profissionais } \\
\text { do magistério }\end{array}$ & $4.727,72$ & $5.882,41$ & $5.476,13$ & $5.705,54$ & $4.904,89$ & $5.189,87$ & $5.397,99$ \\
\hline $\mathrm{RR}$ & $\begin{array}{l}\text { Demais } \\
\text { profissionais }\end{array}$ & $6.328,49$ & $6.284,88$ & $5.809,95$ & $6.213,96$ & $5.253,99$ & $5.496,13$ & $5.492,56$ \\
\hline & Indicador & $74,7 \%$ & $\%$ & $\%$ & $91,8 \%$ & $93,4 \%$ & $94,4 \%$ & $98,3 \%$ \\
\hline & $\begin{array}{l}\text { Profissionais } \\
\text { do magistério }\end{array}$ & $3.581,32$ & $3.585,40$ & $3.908,56$ & $3.725,37$ & $3.713,60$ & $3.678,93$ & $3.666,61$ \\
\hline $\mathrm{PA}$ & $\begin{array}{l}\text { Demais } \\
\text { profissionais }\end{array}$ & $4.646,58$ & $4.767,79$ & $4.850,84$ & $4.286,75$ & $4.281,00$ & $4.137,52$ & $4.687,11$ \\
\hline & Indicador & $77,1 \%$ & $75,2 \%$ & $80,6 \%$ & $86,9 \%$ & $86,7 \%$ & $88,9 \%$ & $78,2 \%$ \\
\hline & $\begin{array}{l}\text { Profissionais } \\
\text { do magistério }\end{array}$ & $4.252,36$ & $4.822,71$ & $5.634,22$ & $5.479,13$ & $4.919,21$ & $4.340,83$ & $4.752,03$ \\
\hline $\mathrm{AP}$ & $\begin{array}{l}\text { Demais } \\
\text { profissionais }\end{array}$ & $4.622,15$ & $4.223,95$ & $5.156,95$ & $4.591,64$ & $4.939,38$ & $5.319,44$ & $5.064,54$ \\
\hline & Indicador & $92,0 \%$ & $114,2 \%$ & $109,3 \%$ & $119,3 \%$ & $99,6 \%$ & $81,6 \%$ & $93,8 \%$ \\
\hline
\end{tabular}




\begin{tabular}{|c|c|c|c|c|c|c|c|c|}
\hline & & & & IDIC & & & & \\
\hline & NDIMENTO & JTO MÉ & MENS & DOS PF & $\overline{F I S S I O}$ & IS DO & GISTÉR & DAS \\
\hline & S PÚBLICAS & EDUCA & O BÁSIC & E DOS L & MAIS P & FISSIO & AIS, CALC & ULADOS \\
\hline & M BASE NOS & DOS D. & NAD CON & ITÍNUA, E & S RESPE & ETIVOS & DICADO & RES DA \\
\hline & & & FTA 17 & $\Delta S \|$ & $12-2018$ & & & tinuacão) \\
\hline & & & & & ANO & & & \\
\hline & & 2012 & 2013 & 2014 & 2015 & 2016 & 2017 & 2018 \\
\hline & $\begin{array}{l}\text { Profissionais } \\
\text { do magistério }\end{array}$ & $3.240,68$ & $3.308,02$ & $3.296,30$ & $3.283,94$ & $3.074,14$ & $3.027,39$ & $3.201,12$ \\
\hline TO & $\begin{array}{l}\text { Demais } \\
\text { profissionais }\end{array}$ & $4.297,27$ & $5.860,02$ & $4.529,40$ & $4.183,91$ & $4.184,29$ & $4.007,95$ & $4.736,97$ \\
\hline & Indicador & $75,4 \%$ & $56,5 \%$ & $72,8 \%$ & $78,5 \%$ & $73,5 \%$ & $75,5 \%$ & $67,6 \%$ \\
\hline & $\begin{array}{l}\text { Profissionais } \\
\text { do magistério }\end{array}$ & $3.246,26$ & $3.392,94$ & $3.591,84$ & $3.782,66$ & $3.725,81$ & $4.071,98$ & $3.893,69$ \\
\hline MA & $\begin{array}{l}\text { Demais } \\
\text { profissionais }\end{array}$ & $4.279,75$ & $4.366,61$ & $3.620,77$ & $3.431,20$ & $3.873,27$ & $4.353,07$ & $3.497,63$ \\
\hline & Indicador & $75,9 \%$ & $77,7 \%$ & $99,2 \%$ & $110,2 \%$ & $96,2 \%$ & $93,5 \%$ & $111,3 \%$ \\
\hline & $\begin{array}{l}\text { Profissionais } \\
\text { do magistério }\end{array}$ & $2.917,30$ & $3.079,92$ & $2.853,24$ & $3.345,70$ & $2.812,72$ & $3.200,86$ & $3.307,25$ \\
\hline PI & $\begin{array}{l}\text { Demais } \\
\text { profissionais }\end{array}$ & $4.182,90$ & $4.070,11$ & $5.253,30$ & $5.041,01$ & $5.481,83$ & $3.941,96$ & $3.633,71$ \\
\hline & Indicador & $69,7 \%$ & $75,7 \%$ & $\%$ & $66,4 \%$ & $\%$ & $81,2 \%$ & $91,0 \%$ \\
\hline & $\begin{array}{l}\text { Profissionais } \\
\text { do magistério }\end{array}$ & $2.485,41$ & $2.616,85$ & $2.783,12$ & $2.691,55$ & $2.717,92$ & $2.796,10$ & $3.133,11$ \\
\hline $\mathrm{CE}$ & $\begin{array}{l}\text { Demais } \\
\text { profissionais }\end{array}$ & $4.385,06$ & $4.910,15$ & $4.917,07$ & $4.543,93$ & $4.383,04$ & $4.329,56$ & $4.705,26$ \\
\hline & Indicador & $56,7 \%$ & $53,3 \%$ & $56,6 \%$ & $59,2 \%$ & $62,0 \%$ & $64,6 \%$ & $66,6 \%$ \\
\hline & $\begin{array}{l}\text { Profissionais } \\
\text { do magistério }\end{array}$ & $3.398,35$ & $3.822,06$ & $4.044,76$ & $4.077,56$ & $3.606,84$ & $4.035,58$ & $4.310,47$ \\
\hline $\mathrm{RN}$ & $\begin{array}{l}\text { Demais } \\
\text { profissionais }\end{array}$ & $4.751,07$ & $5.446,25$ & $4.248,57$ & $4.281,12$ & $4.325,59$ & $4.388,56$ & $4.451,86$ \\
\hline & Indicador & $71,5 \%$ & $70,2 \%$ & $95,2 \%$ & $95,2 \%$ & $83,4 \%$ & $92,0 \%$ & $96,8 \%$ \\
\hline & $\begin{array}{l}\text { Profissionais } \\
\text { do magistério }\end{array}$ & $3.115,04$ & $3.265,24$ & $3.185,97$ & $3.813,85$ & $2.980,39$ & $3.047,34$ & $3.575,14$ \\
\hline PB & $\begin{array}{l}\text { Demais } \\
\text { profissionais }\end{array}$ & $4.750,52$ & $4.342,93$ & $4.510,82$ & $4.840,92$ & $4.216,88$ & $4.820,72$ & $4.899,48$ \\
\hline & Indicador & $65,6 \%$ & $75,2 \%$ & $70,6 \%$ & $78,8 \%$ & $70,7 \%$ & $63,2 \%$ & $73,0 \%$ \\
\hline
\end{tabular}




\begin{tabular}{|c|c|c|c|c|c|c|c|c|}
\hline & & & & IDICE & & & & \\
\hline & NDIMENTO & JTO MÉ & MENSA & L DOS PRC & OFISSIOI & AIS DO I & GISTÉF & DAS \\
\hline & PÚBLICAS & EDUCA & BÁSICA & E DOS D & EMAIS PR & OFISSIO & AIS, CAL & ULADOS \\
\hline & I BASE NOS & DOS DA & IAD CON & ITÍNUA, E & OS RESPE & CTIVOS I & DICADC & RES DA \\
\hline & & & ETA 17 - B & RASIL - 2 & $012-2018$ & & & tinu \\
\hline & & & & & ANO & & & \\
\hline & & 2012 & 2013 & 2014 & 2015 & 2016 & 2017 & 2018 \\
\hline & $\begin{array}{l}\text { Profissionais } \\
\text { do magistério }\end{array}$ & $3.061,93$ & $3.355,08$ & $3.724,04$ & $3.603,93$ & $2.907,99$ & $3.134,85$ & $3.459,10$ \\
\hline $\mathrm{PE}$ & $\begin{array}{l}\text { Demais } \\
\text { profissionais }\end{array}$ & $5.908,04$ & $5.496,95$ & $6.509,70$ & $5.112,78$ & $4.453,98$ & $4.481,07$ & $4.756,46$ \\
\hline & Indicador & $51,8 \%$ & $61,0 \%$ & $57,2 \%$ & $70,5 \%$ & $65,3 \%$ & $70,0 \%$ & $72,7 \%$ \\
\hline & $\begin{array}{l}\text { Profissionais } \\
\text { do magistério }\end{array}$ & $3.257,32$ & $3.505,62$ & $3.442,96$ & $3.660,76$ & $3.263,90$ & $3.014,44$ & $3.299,83$ \\
\hline $\mathrm{AL}$ & $\begin{array}{l}\text { Demais } \\
\text { profissionais }\end{array}$ & $3.784,89$ & $3.862,18$ & $4.858,48$ & $4.750,88$ & $4.261,64$ & $3.942,43$ & $3.932,83$ \\
\hline & Indicador & $86,1 \%$ & $90,8 \%$ & $70,9 \%$ & $77,1 \%$ & $76,6 \%$ & $76,5 \%$ & $83,9 \%$ \\
\hline & $\begin{array}{l}\text { Profissionais } \\
\text { do magistério }\end{array}$ & $5.316,00$ & $5.122,41$ & $4.895,14$ & $4.470,39$ & $4.010,77$ & $5.140,18$ & $4.271,79$ \\
\hline SE & $\begin{array}{l}\text { Demais } \\
\text { profissionais }\end{array}$ & $4.704,75$ & $5.604,83$ & $6.352,53$ & $5.122,07$ & $5.685,36$ & $5.674,96$ & $4.630,53$ \\
\hline & Indicador & $113,0 \%$ & $91,4 \%$ & $77,1 \%$ & $87,3 \%$ & $5 \%$ & $90,6 \%$ & $92,3 \%$ \\
\hline & $\begin{array}{l}\text { Profissionais } \\
\text { do magistério }\end{array}$ & $3.139,87$ & $3.473,79$ & $3.880,11$ & $4.163,90$ & $3.373,88$ & $3.711,60$ & $3.731,15$ \\
\hline $\mathrm{BA}$ & $\begin{array}{l}\text { Demais } \\
\text { profissionais }\end{array}$ & $5.223,23$ & $4.653,04$ & $4.273,50$ & $4.600,69$ & $4.215,26$ & $4.645,03$ & $3.935,08$ \\
\hline & Indicador & $60,1 \%$ & $74,7 \%$ & $90,8 \%$ & $90,5 \%$ & $80,0 \%$ & $79,9 \%$ & $94,8 \%$ \\
\hline & $\begin{array}{l}\text { Profissionais } \\
\text { do magistério }\end{array}$ & $3.325,96$ & $3.233,06$ & $3.308,02$ & $3.413,73$ & $3.196,05$ & $3.580,86$ & $3.732,49$ \\
\hline MG & $\begin{array}{l}\text { Demais } \\
\text { profissionais }\end{array}$ & $4.731,03$ & $4.802,27$ & $4.820,77$ & $4.712,16$ & $4.371,67$ & $4.493,79$ & $4.446,70$ \\
\hline & Indicador & $70,3 \%$ & $67,3 \%$ & $68,6 \%$ & $72,4 \%$ & $73,1 \%$ & $79,7 \%$ & $83,9 \%$ \\
\hline & $\begin{array}{l}\text { Profissionais } \\
\text { do magistério }\end{array}$ & $3.638,89$ & $3.622,35$ & $3.433,43$ & $3.487,55$ & $3.158,53$ & $3.473,67$ & $3.462,93$ \\
\hline ES & $\begin{array}{l}\text { Demais } \\
\text { profissionais }\end{array}$ & $4.672,24$ & $4.886,88$ & $4.903,79$ & $4.484,45$ & $4.439,91$ & $4.700,31$ & $4.707,85$ \\
\hline & Indicador & $77,9 \%$ & $74,1 \%$ & $70,0 \%$ & $77,8 \%$ & $71,1 \%$ & $73,9 \%$ & $73,6 \%$ \\
\hline
\end{tabular}




\begin{tabular}{|c|c|c|c|c|c|c|c|c|}
\hline & & & & B & & & & \\
\hline & DDIMENTC & TO ME & MENSA & DOS PRC & DFISSIO & SDO & GISTÉ & DA \\
\hline & SÚBICAS & EDUCAC & BÁsica & FDos & EMAISPRE & DEISION & Ais caic & ULADOS \\
\hline & BASE NO & $S D$ & D CON & TÍNUA, E & OS RESPE & CTIVOS IN & DICADO & ES DA \\
\hline & & & ETA 17 - B & RASIL - 2 & $012-2018$ & & & \\
\hline & & & & & ANO & & & \\
\hline & & 2012 & 2013 & 2014 & 2015 & 2016 & 2017 & 2018 \\
\hline & $\begin{array}{l}\text { Profissionais } \\
\text { do magistério }\end{array}$ & $4.162,45$ & $4.810,14$ & $4.521,46$ & $4.322,66$ & $4.256,92$ & $4.798,88$ & $4.820,16$ \\
\hline RJ & $\begin{array}{l}\text { Demais } \\
\text { profissionais }\end{array}$ & $5.589,73$ & $5.321,65$ & $5.671,95$ & $5.586,83$ & $5.583,48$ & $5.709,52$ & $6.102,36$ \\
\hline & Indicador & $74,5 \%$ & $90,4 \%$ & $79,7 \%$ & $77,4 \%$ & $76,2 \%$ & $84,1 \%$ & $79,0 \%$ \\
\hline & $\begin{array}{l}\text { Profissionais } \\
\text { do magistério }\end{array}$ & $3.504,22$ & $3.804,64$ & $3.667,03$ & $3.771,55$ & $3.550,41$ & $3.661,84$ & $4.262,70$ \\
\hline $\mathrm{SP}$ & $\begin{array}{l}\text { Demais } \\
\text { profissionais }\end{array}$ & $5.730,35$ & $5.482,86$ & $5.578,14$ & $5.716,13$ & $5.326,07$ & $5.402,63$ & $5.807,27$ \\
\hline & Indicador & $61,2 \%$ & $69,4 \%$ & $65,7 \%$ & $66,0 \%$ & $66,7 \%$ & $67,8 \%$ & $73,4 \%$ \\
\hline & $\begin{array}{l}\text { Profissionais } \\
\text { do magistério }\end{array}$ & $3.792,47$ & $4.075,56$ & $4.171,48$ & $3.967,15$ & $4.098,11$ & $4.538,78$ & $4.495,29$ \\
\hline PR & $\begin{array}{l}\text { Demais } \\
\text { profissionais }\end{array}$ & $4.671,35$ & $4.501,92$ & $4.365,27$ & $4.693,05$ & $4.401,26$ & $4.478,43$ & $4.797,90$ \\
\hline & Indicador & $81,2 \%$ & $90,5 \%$ & $95,6 \%$ & $84,5 \%$ & $93,1 \%$ & $101,3 \%$ & $93,7 \%$ \\
\hline & $\begin{array}{l}\text { Profissionais } \\
\text { do magistério }\end{array}$ & $3.180,94$ & $3.243,09$ & $3.266,07$ & $3.427,33$ & $3.301,99$ & $3.565,41$ & $3.442,49$ \\
\hline SC & $\begin{array}{l}\text { Demais } \\
\text { profissionais }\end{array}$ & $4.230,86$ & $4.041,35$ & $4.267,87$ & $4.620,16$ & $3.970,14$ & $4.450,17$ & $4.154,85$ \\
\hline & Indicador & $75,2 \%$ & $80,2 \%$ & $6,5 \%$ & $74,2 \%$ & $83,2 \%$ & $80,1 \%$ & $82,9 \%$ \\
\hline & $\begin{array}{l}\text { Profissionais } \\
\text { do magistério }\end{array}$ & $3.470,47$ & $3.652,82$ & $3.465,02$ & $3.792,81$ & $3.619,08$ & $3.968,53$ & $4.018,32$ \\
\hline RS & $\begin{array}{l}\text { Demais } \\
\text { profissionais }\end{array}$ & $5.250,50$ & $5.253,68$ & $5.315,80$ & $5.085,04$ & $5.169,64$ & $5.351,34$ & $5.312,02$ \\
\hline & Indicador & $66,1 \%$ & $69,5 \%$ & $65,2 \%$ & $74,6 \%$ & $70,0 \%$ & $74,2 \%$ & $75,6 \%$ \\
\hline & $\begin{array}{l}\text { Profissionais } \\
\text { do magistério }\end{array}$ & $4.198,58$ & $4.162,44$ & $4.553,70$ & $4.629,11$ & $4.345,36$ & $4.745,28$ & $4.997,89$ \\
\hline MS & $\begin{array}{l}\text { Demais } \\
\text { profissionais }\end{array}$ & $3.842,25$ & $4.542,50$ & $4.305,76$ & $4.783,91$ & $4.028,43$ & $4.378,85$ & $4.611,83$ \\
\hline & Indicador & $109,3 \%$ & $91,6 \%$ & $105,8 \%$ & $96,8 \%$ & $107,9 \%$ & $108,4 \%$ & $108,4 \%$ \\
\hline
\end{tabular}




\begin{tabular}{|c|c|c|c|c|c|c|c|c|}
\hline & & & & NDICE B & & & & \\
\hline & NDIMENTO & UTO MÉ & O MENS & L DOS PR & DFISSIO & AIS DO N & AGISTÉR & O DAS \\
\hline & PÚBLICAS & EDUCA & O BÁSIC & E DOS D & EMAIS PR & OFISSION & AIS, CALC & ULADOS \\
\hline & I BASE NOS & ADOS DA & PNAD CON & TÍNUA, E & OS RESPE & CTIVOS & DICAD & RES DA \\
\hline & & & META 17 - & 2ACH - ? & $012-2018$ & & & onclusão) \\
\hline & & & & & ANO & & & \\
\hline & & 2012 & 2013 & 2014 & 2015 & 2016 & 2017 & 2018 \\
\hline & $\begin{array}{l}\text { Profissionais } \\
\text { do magistério }\end{array}$ & $3.860,86$ & $3.636,10$ & $3.826,91$ & $3.704,16$ & $3.922,10$ & $4.013,76$ & $4.505,51$ \\
\hline MT & $\begin{array}{l}\text { Demais } \\
\text { profissionais }\end{array}$ & $5.172,21$ & $4.725,95$ & $4.828,98$ & $4.794,33$ & $4.062,99$ & $4.576,80$ & $4.219,38$ \\
\hline & Indicador & $74,6 \%$ & $76,9 \%$ & $79,2 \%$ & $77,3 \%$ & $96,5 \%$ & $87,7 \%$ & $106,8 \%$ \\
\hline & $\begin{array}{l}\text { Profissionais } \\
\text { do magistério }\end{array}$ & $3.545,47$ & $3.617,52$ & $3.716,57$ & $3.877,57$ & $3.335,05$ & $3.527,95$ & $4.269,69$ \\
\hline GO & $\begin{array}{l}\text { Demais } \\
\text { profissionais }\end{array}$ & $4.289,35$ & $4.173,61$ & $4.340,08$ & $4.374,27$ & $3.931,16$ & $4.048,59$ & $4.325,80$ \\
\hline & Indicador & $82,7 \%$ & $86,7 \%$ & $85,6 \%$ & $88,6 \%$ & $84,8 \%$ & $87,1 \%$ & $98,7 \%$ \\
\hline & $\begin{array}{l}\text { Profissionais } \\
\text { do magistério }\end{array}$ & $7.315,15$ & $8.059,32$ & $6.945,56$ & $7.487,94$ & $6.439,28$ & $7.288,59$ & $6.730,19$ \\
\hline $\mathrm{DF}$ & $\begin{array}{l}\text { Demais } \\
\text { profissionais }\end{array}$ & $10.132,72$ & $10.181,03$ & $9.285,68$ & $9.503,18$ & $8.871,48$ & $8.793,74$ & $8.611,67$ \\
\hline & Indicador & $72,2 \%$ & $79,2 \%$ & $74,8 \%$ & $78,8 \%$ & $72,6 \%$ & $82,9 \%$ & $78,2 \%$ \\
\hline
\end{tabular}

Fonte: Elaboração própria com base em dados da Pnad Contínua/IBGE 2012-2018 - $2^{\circ}$ trimestre. Nota: valores corrigidos pela variação do IPCA/IBGE, com preços de 2018. 
